Portland State University

PDXScholar

Spring 6-5-2019

\title{
Impactful Care: Addressing Social Determinants of Health Across Health Systems
}

Nicole Lisa Friedman

Portland State University

Follow this and additional works at: https://pdxscholar.library.pdx.edu/open_access_etds

Part of the Anthropology Commons, and the Community Health Commons Let us know how access to this document benefits you.

\section{Recommended Citation}

Friedman, Nicole Lisa, "Impactful Care: Addressing Social Determinants of Health Across Health Systems" (2019). Dissertations and Theses. Paper 5073.

https://doi.org/10.15760/etd.6957

This Thesis is brought to you for free and open access. It has been accepted for inclusion in Dissertations and Theses by an authorized administrator of PDXScholar. Please contact us if we can make this document more accessible: pdxscholar@pdx.edu. 
Impactful Care:

Addressing Social Determinants of Health Across Health Systems

\title{
by
}

Nicole Lisa Friedman

A thesis submitted in partial fulfillment of the requirements for the degree of

\author{
Master of Science \\ in \\ Anthropology \\ Thesis Committee: \\ Charles H. Klein, Chair \\ Jeremy Spoon \\ Matthew P. Banegas \\ Portland State University \\ 2019
}




\section{Abstract}

There is emerging evidence that addressing health-related social needs through enhanced clinical-community linkages can improve health outcomes and reduce costs. Unmet health-related social needs, such as food insecurity, inadequate or unstable housing, and lack of access to transportation may increase the risk of developing chronic conditions, reduce an individual's ability to manage these conditions, increase health care costs, and lead to avoidable health care utilization. In response, work on social needs is happening across large health systems in the United States, but the pace of progress is slow and accountability is diffuse.

The goal of this applied research project is to examine Kaiser Permanente Northwest's patient navigator program as a case study for how health systems can transform into organizations that bridge clinical, social and behavioral health and redefine what it means to be a prevention-oriented delivery system. Kaiser Permanente Northwest (KPNW) provides high quality, patient-centered care to over 550,000 medical members and 240,000 dental members in Oregon and Southwest Washington. In conjunction with the Care Management Institute, KPNW created a patient navigator administered, social needs screening tool called "Your Current Life Situation" (YCLS). This thesis focuses on the data collected from this screening tool with an emphasis on operations management, workflows, and the technical tools that have been supported to do this work. The analysis uses semi-structured qualitative interviews from patient navigators, physicians, social workers, community organizations and members to better 
understand the experience of social needs screening in clinical practice and its impact on members and community partners as they receive referrals for services outside the health care delivery system. Through using anthropological theory and methods, I seek to help health systems think and act differently by elevating the voice and experience of the community and translating vulnerable populations' needs into a language that can be integrated within multiple systems of care. 
Table of Contents

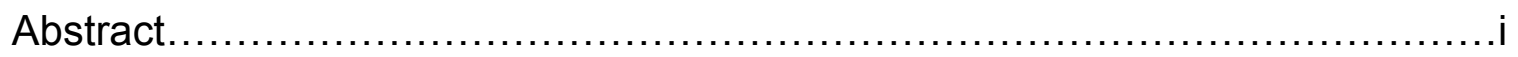

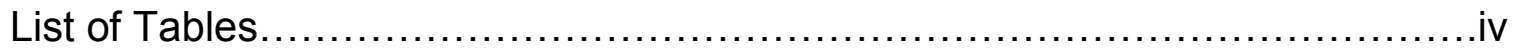

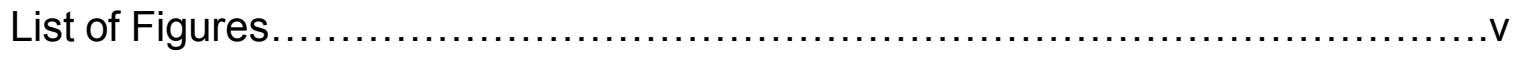

Chapter 1

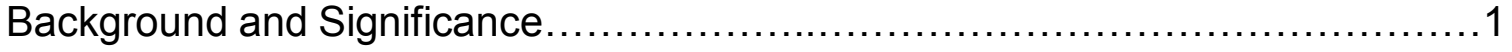

Chapter 2

Operationalizing Social Determinants of Health in the Clinical Care Setting......15

Chapter 3

Evaluation of a Targeted Navigator Pilot to Address Patient Medical Care Cost

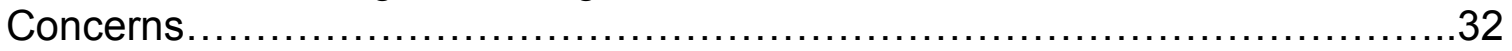

Chapter 4

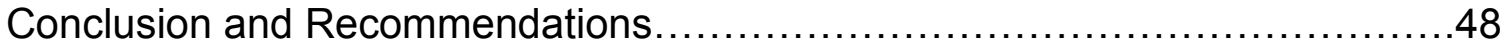

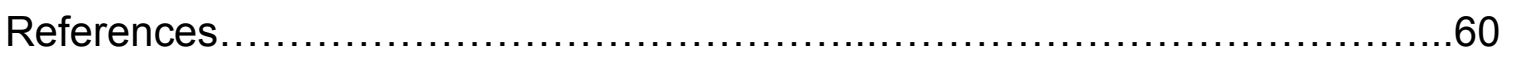

Appendix A. Your Current Life Situation Questionnaire ...........................65 
List of Tables

Table 1. Social Determinants of Health Data Collected in EHR, Corresponding ICD-10 Z-codes, and Examples of Use ........................................52

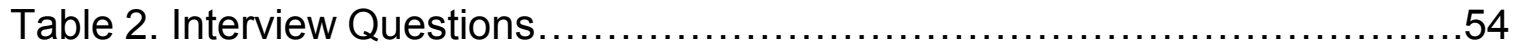

Table 3. Member Needs at Baseline ..........................................55 
List of Figures

Figure 1. Community Resource Referral SmartSet: ICD-10 Z-Codes - Social

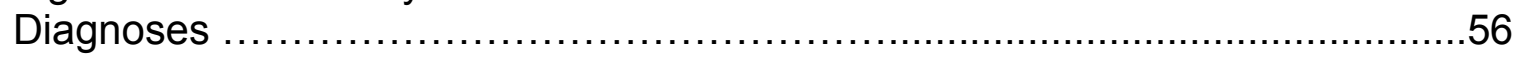

Figure 2. KPNW Navigation Model: A model for addressing social needs........57

Figure 3. Impact of Financial Health Pilot on Member Satisfaction ...............58

Figure 4. Provider Opinions on Member Medical Costs...........................59 


\section{Chapter 1 \\ Background and Significance}

Social determinants of health $(\mathrm{SDOH})$ are factors outside of health care that impact individual and population health outcomes, including economic opportunities, resources, and social support at individual and community levels (World Health Organization n.d.). Social determinants of health generate poor patient outcomes and increased health care costs. Based on meta-analysis of over 50 studies, researchers have found that social factors such as lack of education, racial segregation and poverty are directly related to over one-third of the deaths in the U.S each year (Weil 2017). However, despite a wealth of evidence on the impact of social determinants on health outcomes and cost, health care systems often lack robust tools to screen for social needs and strategies to standardize measurement of social determinants within electronic health records in a way that allows for data collection and targeted clinical interventions (Gottlieb 2016).

This thesis focuses on Kaiser Permanente Northwest (KPNW), an integrated health care delivery system that provides care to more than 600,000 members in Oregon and Southwest Washington through its 34 medical offices and two hospitals. Like many health care providers in the United States today, KPNW is committed to developing tools and strategies to identify and address social risks as part of a population health approach to care and care delivery. In this framework, social determinant data is included alongside clinical data to develop a predictive model to better identify high-risk populations who may 
benefit from care and case management programs. In addition, the Affordable Care Act $(A C A)$ accelerated the maturation of the primary care medical home at KPNW. This model of care holds providers and delivery systems accountable for population rather than individual health outcomes (Gottlieb 2016) and involves the utilization of value-based care incentives that include the stratification of highcost patients who use emergency room services to address chronic conditions such as asthma, diabetes, heart failure, obesity and depression. However, a lack of social determinant data in clinical care facilities impairs accurate risk assessment and effective management of such health conditions.

For example, Dr. M, a family physician at KPNW's Rockwood clinic, recounted to me the case of one of her members who was consistently losing weight. As he was an older gentleman, she followed best practice and had his bone density tested, ordered multiple labs, and even referred him to a nutritionist and considered a CAT scan to look for tumors. However, it came up in one of Dr. M's follow-up visits that this patient was food insecure - he was only going shopping once a month when he received his Social Security check and was mostly living on canned beans. Having this information available early on in treatment could have informed new interventions that responded to underlying $\mathrm{SDOH}$ rather than adding more expensive clinical care that leaves root causes unaddressed (Gottlieb 2016). In this manner, addressing social needs can enhance the wellbeing of Kaiser Permanente members, promote affordability, and present an opportunity to broaden Kaiser's value proposition by addressing person and family centered goals. 
The Affordable Care Act and Emerging Models of Care at Kaiser Permanente Northwest

The 2010 Affordable Care Act (ACA) provided health coverage to millions of Americans across the United States by expanding Medicaid and creating a marketplace where individuals could purchase a plan based on their income. Nonetheless, having health insurance and a primary care medical home does not necessarily translate into access to appropriate care, and many of the newly insured population still go to the emergency room for routine treatment. This reality is demonstrated by cases such as a patient who went to the Kaiser Permanente Sunnyside emergency room three times in ten days to treat an eye infection. Sharing a car with six family members who could not take off work to take her to the clinic between 8 a.m. to 5 p.m., she instead would go to the $24 / 7$ Emergency Department at hours convenient for her family.

Addressing such $\mathrm{SDOH}$ is fundamentally different from treating medical problems. Health care systems are well equipped with screening tools, clinical resources, evidence-based medicine, diagnostics, labs, imaging, pharmaceuticals and other biomedical technologies to detect and treat disease (Garg 2016). As health systems increase social screening in clinical care settings to improve population health, they require standardized, measurable and actionable data on social determinants similar to what is currently available for clinical assessments. These patient and population-level data require strategic partnerships with referral agencies who have the resources and expertise to address identified social needs (Lindau et al. 2016). Without this integration, 
health systems are at risk of putting patients through unintended harm by screening for social needs without a resource to help them.

Seeking to address these gaps, in early 2016 , a multidisciplinary team of operations, clinical, and research staff at KPNW came together to build and implement a standardized model for assessing and addressing patients' social needs within the parameters imposed by the ACA. The team determined that the first step in addressing patients' social needs was to document and measure those needs in a standardized way. In conjunction with the Care Management Institute, KPNW created a social needs screening tool called "Your Current Life Situation" (YCLS; see Appendix A). The YCLS consists of nine core questions related to housing, finances, food insecurity, transportation, activities of daily living, and stress, with an additional 21 questions/follow-up items that a patient may be asked if they screen positively for a social need.

The team then implemented a Phase I pilot study focused on proactively screening three distinct patient populations using the YCLS questionnaire: (1) complex care/rising risk patients, (2) emergency department (ED) utilizers and hospitalized patients, and (3) new KPNW members. When providers discovered a patient had an unmet social need during a routine visit, they were able to refer the member to a Patient Navigator for a full YCLS assessment and an appropriate community referral. Building on the Phase I pilot study, KPNW has subsequently worked with its electronic health records (EHR) vendor, Epic, to develop a set of three SDOH SmartSets to help facilitate electronic 
documentation of social needs screening and referrals identified through the YCLS and other interactions with members.

\section{Research Questions and Methods}

This thesis examines the implementation and outcomes of the pilot YCLS/patient navigator program and seeks to answer the following questions:

1) How does screening for social needs inform socially informed care?

2) For members who have difficulty affording medical care, can nonclinical patient navigators increase patient satisfaction with care and cost of care by addressing their social needs?

3) Does integrating navigators within the health system reduce social and logistical suffering for patients and providers?

My analysis is based on patient-level social determinant of health data, patient chart review, and interview data collected from 2016 to 2018. As an employee of Kaiser Permanente with senior level sponsorship to carry out this research, I was able to access to personnel, technology, data and analytic support, including the Kaiser Center for Health Research Biostatistics Core, to support my study design, data collection, data management, and data analysis.

Patient-level Social Determinant of Health Data. I deployed five of my current patient navigator staff in the emergency department to screen patients for social determinants of health using a validated screening tool that is fully integrated into the electronic health record (Appendix A). Focusing on nonemergency ED visits, the navigators screened nearly two thousand patients from January 2017 to June 2017 and tracked social determinants of health using ICD- 
10 codes based on participant responses to the screening (Table 1). I also collected quantitative and qualitative data from an automated report that I receive weekly based on information pulled from the electronic medical record. These reports not only identify patient health information, but also show social determinant codes (Figure 1), community resources provided, referral agencies, and referral outcomes. I used this information to document the top needs identified using social codes, the volume of referrals made, and the capacity of agencies to address referrals based on outcome data as to whether the need was met by the referrals provided.

Patient Chart Review. Seven patient navigator supervisors and five Oregon Health and Science University capstone students reviewed 300 charts over the six-month study period. The team pulled de-identified data from the electronic medical record for patients who had multiple social diagnosis (based on social codes) and multiple complex co-morbidities (based on disease codes) to understand how social risk factors impact the acuity of a patient. This data informed recommendations for including social factors to predict and stratify risk, improve panel management, and guide clinical intervention at the population health level.

Interviews. A team consisting of myself, a Kaiser-based project coordinator, and the OHSU capstone team collected qualitative data through semi-structured interviews with Kaiser providers $(n=22$, including five primary care medical providers, two Emergency Department physicians, five social workers and ten patient navigators), patient testimonials and case studies $(n=12)$, 
and interviews with community agencies $(n=6)$. The goal of these interviews and patient case studies was to understand the level of partnership between KPNW and other types of service providers, such as public health programs, social services agencies, and community-based organizations (see Table 2)

Data Analysis. This thesis integrates these mixed methods data into two overarching case studies. Chapter 2 uses qualitative interview data to examine the impact of social needs screening and increased referral volume on patients, KPNW providers and partner community organizations. Chapter 3 quantitatively and qualitatively assesses a targeted intervention for a population with selfreported medical financial concerns to see if addressing financial needs increases satisfaction with care and cost of care. Because of the ethical imperative to provide services for patients who have unmet social needs, there is no matched control for the social determinant cohort analysis in the Chapter 3 case study. Instead, I used a pre/post design that analyzed emergency room utilization, no-show rate in primary care, and insurance coverage before and after the social needs screening and navigator intervention (i.e., the connection to community resources). The level of partnership compared to the volume of referrals enabled me to identify potential risks for logistical suffering and social triage and highlight opportunities to develop comprehensive system capital. Based on patient calls, face-to-face office visits, and secure patients e-mails, we also compared how many navigator interventions it takes to make a referral lead to a community connection. Such data provides much needed information on 
community capacity and the scalability of the social determinant of care approach.

\section{Theoretical Framework}

Clinical and public health experts have found that coordinated care for chronic health conditions such as HIV infection, hypertension and hepatitis C can be improved by systematically addressing multiple steps in a continuum of care that begins with recognition of the condition and the culminates in the outcomes of interest. This framework is being applied at Kaiser Permanente Northwest to describe the steps necessary to address members' basic social needs and organize existing evidence of programs that follow this model.

The eight steps in the care continuum for basic social needs are:

1. Select the population or sub-populations of Kaiser members to assess for a range of basic social needs and identify community organizations that address those needs.

2. Identify specific social needs in Kaiser members through systematic surveys of the populations identified (see Appendix A)

3. Develop clinical and population-based workflows to refer members to community organizations that can assist in fulfilling basic social needs.

4. Establish bi-directional communication channels with community organizations which confirm that members have been linked successfully to those organizations and track the resolution of basic needs.

5. Assure that members obtain resources necessary to fulfill their basic social needs. 
6. Assess the impact of fulfilling basic social needs on health, clinical outcomes, satisfaction and retention of Kaiser members.

7. Assess the impact of fulfilling basic social needs on utilization of health care services and the costs of care

8. Disseminate effective programs within Kaiser and to other health care systems.

Each step of the continuum is associated with specific barriers that must be addressed to achieve population health goals. Failure to address those challenges produces "voltage drops" between steps, which cumulatively erode the ability of health care organizations and their community collaborators to achieve the desired outcomes. By situating this care continuum framework within three inter-related anthropological frameworks - social suffering/structural violence, social triage, and community vitality - we can deepen our understanding of the content of specific barriers and better understand why these voltage drops occur.

\section{Social Suffering and Structural Violence}

Nearly all medical providers are dedicated to reducing suffering for their patient. In the case of biomedicine, care has most often focused on reducing physical symptoms of suffering by diagnosing illness and treating the disease with clinical interventions. However, social suffering looks different than physical pain, and health care systems have not been trained to diagnose and treat symptoms of socio-economic suffering. To better understand and address social suffering, care delivery needs to consider the role of structural violence, defined 
as "any situation where an individual is avoidably prevented from achieving his or her social, economic, or biological potential" (Vanderwarker and Wilson 2016, 2). As health care systems begin assessing the severity of unmet social needs, triage their patients based on these risk factors, and provide community referrals, they will constantly need to respond to critical question Paul Farmer (2001) raises, namely, what suffering needs are most critical, and what resources are available to address it?

According to the 2015 State of Black Oregon report (Urban League of Portland 2015), racial disparities in health, housing instability, unemployment and education are pronounced and widening. Today, 30\% of African Americans live below the poverty line compared to $11 \%$ of white families, and $45 \%$ of African American families reported food insecurity compared to $18 \%$ of whites. Similarly, the 2014 Multnomah County Report Card on Racial and Ethnic Disparities showed significant socio-economic inequities across communities of color (Multnomah County Health Department 2014). If health systems seek to reduce specific barriers to achieve population health and reduce the risk of voltage drops, it is essential to understand how structural violence exacerbates these barriers.

\section{Social Triage}

The alarming disparities highlighted in the State of Oregon and Multnomah County reports vividly demonstrate how structural violence supports continued marginalization of and discrimination towards those who are suffering the hardest. In this paradigm, social needs such as housing, food, and other 
hardships are symptoms of structural violence that are perpetuated by broader socio-economic and political circumstances (Farmer 2001; VanDerwarker and Wilson 2016). Social service and health care providers can reduce "flare up" in symptoms by giving food boxes, bus vouchers and shelter information, but this will only relieve the symptoms and not the cause of human suffering. Moreover, as health care providers employ methods and tools to help them triage patients based on unmet social needs, the acuity of the patient will change, and this may cause shifts in resource allocation. As Simmons and Casper argue (2012), for both social and health services, the application of these types of cost-benefitanalyses based on neoliberal rationalities may contribute to making many marginalized populations invisible. In such situations, resources may go to those in crisis, such as the patient who is currently homeless or without food, rather than investing in resources or upstream interventions to prevent vulnerable populations from becoming homeless or food insecure in the first place.

Health care systems, including Kaiser Permanente, currently address unmet social needs through referrals to community-based organizations and governmental social service agencies. Many clinicians, however, are reluctant to screen for social determinants if they do not have resources to give the patient, and there is a strong emphasis on providing patients with multiple options when providing resources. At the same time, health care delivery and social service provision in the United States is underpinned by a neoliberal ideology of individualism, choice, productivity and self-responsibility that assumes that anyone can get care and that is their responsibility to do so. Furthermore, the 
current neoliberal emphasis on individual choice and responsibility may not help us understand patient behavior in following up on referrals, which instead requires examining the social, political and economic factors that impact choice (Nguyen and Peschard 2003). Moreover, such individual responsibility approaches often end up blaming and shaming populations with low socioeconomic status and subjecting disempowered communities to "interventions that medicalize social forms of suffering" (Nguyen and Peschard 2003, 458). As a result, neoliberal discourses in health care can be dangerous because they downplay discriminatory practices and foster a vision in which patients who do not successfully connect to a referral are themselves seen as "obstacles in diagnosis, treatment, compliance and outcome" (Kleinman 1988, 69). Community Vitality

To successfully address social needs, health systems need to become part of a new and expanded ecosystem that integrates a large number of community-based organizations into medical care and social support. As Rose argues, both hospitals and community-based organizations are structures of governance that through "translation" align authoritative objectives with personal projects of groups, organizations or individuals (Rose, 2006). As health care providers become a part of a new ecosystem, it is imperative that they examine the values, goals and preferences of different stakeholders as well as the varying power dynamics between patients, health systems and community organizations. Here, Kleinman's recommendation of a "client centered approach" to health care delivery can offer providers a framework to "better interpret how illness and 
clinical reality are organized in a local cultural system of meanings, norms and power" $(1988,59)$. Such a community-driven approach to care delivery can facilitate a shared vision of the community as a partner to a solution rather than an obstacle to improving health outcomes.

\section{Significance}

Kaiser Permanente Northwest (KPNW) is an integrated health care system that has implemented a comprehensive approach toward addressing the $\mathrm{SDOH}$ of its patients. Adopted strategies, as mentioned earlier, include the use of ICD-10 social diagnostic codes (z-codes), the integration of new roles (nonclinical navigators) and the development of novel workflows via non-clinical patient navigators to address patients' SDOH through community resource referrals.

Successful integration of SDOH data in EHRs may enable more effective care management and treatment strategies for patients, provide more effective population health approaches, and inform new treatments and interventions as pathways linking SDOH to disease processes are discovered (Fraze et al. 2016; National Academies of Sciences, Engineering, and Medicine 2017). However, despite the promise of this work, there is limited information about the strategies employed by health care systems to identify and address $\mathrm{SDOH}$, and how these strategies may or may not mitigate social suffering at the individual level (Gold et al. 2017).

To address the existing knowledge gap, I seek to contribute to generalizable knowledge that will inform the development of effective and 
actionable strategies to identify and address SDOH within clinical settings to improve the health of patients and communities. I argue that addressing social determinants of health through an integrated system of standardized patient-level codes, patient navigators, and community-based services can improve health outcomes, reduce cost, and reduce logistical suffering at both patient and provider levels. 


\title{
Chapter 2
}

\section{Operationalizing Social Determinants of Health in the Clinical Care Setting}

\begin{abstract}
Kaiser Permanente has a long history of conducting research aimed at better understanding how to improve medical care and quality of life. In doing this research, the organization realized that many of the barriers to obtaining good health reside outside of the medical system such as access to housing, nutritious food, and a safe environment.

\section{Navigators in the Health Care Setting and Processes for Identifying SDOH}

There are multiple points within the health care encounter when health care staff initially identify patients' SDOH. These include: (1) non-clinical staff members who interact with patients during the health care visit, but outside of the clinical encounter (e.g., a registration/check-in representative who learns that a patient has a transportation need); (2) clinical staff members who identify patients with $\mathrm{SDOH}$ as part of the clinical encounter (e.g., a nurse learns that a patient is currently homeless and unable to pay for their prescribed medication); or (3) patients who are assessed for SDOH proactively as part of an initial assessment for care management or as part of a targeted outreach for patients who may be at risk of having social barriers to care. The latter scenario might include patients who have "bounced back" to the emergency room twice within five days and receive a proactive outreach call from a Patient Navigator to assess issues such as lack of transportation or inability to pay for medications.
\end{abstract}


At KPNW, non-clinical Patient Navigators play an integral role on the health care team, engaging with patients to identify and address patients' SDOH (Figure 2). Patient Navigators are part of interdisciplinary care teams, where they work alongside nurses, social workers, behavioral health specialists, clinicians and other health care staff to help patients connect with needed resources. Patient Navigators are non-clinically licensed health care staff members who are frontline public health workers. The majority of Patient Navigators at KPNW have a bachelors or graduate degree in public health, social work, community health and/or other social science/humanities disciplines (e.g., anthropology) and are trained in motivational interviewing, trauma-informed care and mental health first aid, among other specialties. All KPNW Patient Navigators obtain state (i.e., Oregon Health Authority) and federal training and certification as Certified Application Counselors to help patients look for health insurance coverage options (e.g., Medicaid, Children's Health Insurance Program and the Health Insurance Marketplace), and complete eligibility and enrollment forms for members. Many Patient Navigators are also certified community health workers. KPNW Patient Navigators represent diverse cultural backgrounds, with over seven languages spoken across the team, including English, Mandarin Chinese, Spanish, Russian and multiple African dialects.

Referrals to Patient Navigators for SDOH follow-up most often occur through direct contact (i.e., phone or in-person) or an EHR-based notification from the referring non-clinical or clinical staff member. These referrals come from staff members in various roles (e.g., membership services, social work, pre- 
registration) and departments within the health care system (i.e., primary care, emergency, other specialty care). Upon receiving the SDOH referral, the Patient Navigator engages the patient by phone, email, or in-person, when possible. In many instances, the Patient Navigator can meet with the patient on the same day during their clinical encounter. When same-day contact is not possible, the Patient Navigator contacts the patient by phone or email within 48 hours of the $\mathrm{SDOH}$ referral. Once in contact with the patient, the Patient Navigators use the standardized and vetted YCLS social needs assessment to understand, identify, and prioritize SDOH. Additionally, Patient Navigators educate and inform patients about KPNW-specific and community resources available to meet the identified SDOH and coordinate with patients to help facilitate connections to resources.

\section{SDOH Data and ICD-10 z-codes}

Identified SDOH are documented in the EHR using a taxonomy of approximately twenty-four ICD-10 z-codes (Table 1). ICD-10 z-codes are grouped into four overarching SDOH domains - social, economic, environmental and health education - and example scenarios of when each z-code may be used to identify a patient's SDOH. ICD-10 z-codes (z00-z99) are referred to as "factors influencing health status and contact with health services." These codes may be used to identify reasons for a health care encounter, as first-listed or principal diagnosis (only certain z-codes), as well as to provide useful information on the circumstances that could affect a patient's health care and treatment (Centers for Medicare and Medicaid Services and National Center for Health Statistics 2014). The SDOH SmartSet used by KPNW helps facilitate quick data 
entry to support clinical flow. The z-code, on the other hand, enables extraction of SDOH data from the EHR for use in clinical (e.g., quality assurance), operational, (e.g., reporting) and research (e.g., empirical studies) purposes.

Often, providers and navigators enter more than one z-code into the EHR because patients can have multiple unmet SDOH that are interrelated. A patient who is homeless, for example, may also have financial problems, lack material resources, and be food insecure. In such a scenario, the use of multiple z-codes supports the identification of co-occurring social risk factors. Patient Navigators strive to prioritize and address these documented SDOH based on patient preferences as well as perceived level of need, opportunity for acute intervention, and availability of resources.

\section{SDOH Community Resources Referrals}

To address the identified SDOH of patients, KPNW has developed SDOH SmartSets within the EHR for community resource referral and tracking. Epic defines the SmartSet as "a group of orders and other elements, such as notes, chief complaints, SmartGroup Panels, and levels of service, that are commonly used together to document a specific type of visit" (Laura Gottlieb, personal communication with author, April 2018). The KPNW SDOH SmartSets were developed by Kaiser Information Technology and clinical and operational stakeholders. KPNW Patient Navigators use the SDOH SmartSet to identify $\mathrm{SDOH}$ and make a referral for a patient to a targeted community resource(s) in effort of helping meet the SDOH. The KPNW Community Resource Referral SmartSet is generated with a list of over 200 resources, both internal (i.e. 
resources offered at KPNW, like the Medical Financial Assistance Program) and external (e.g., community-based organizations). Examples of the Community Resource Referral SmartSet are shown for food insecurity (Figure 1, top panel) and homelessness (z59.0) or housing or economic circumstance (Figure 1, bottom panel). The Community Resource Referral SmartSet associates the identified SDOH with a specific resource(s) and provides the opportunity to prioritize the patient need as "routine" or "immediate," with new resources added or removed as appropriate.

The third component is the SDOH Community Resource Summary Progress Notes SmartSet 2, which provides a comprehensive overview of the patient's recommendations for resources and health care services. In this progress note, the health care members collects initial information about the patient's SDOH, referrals to other health care staff members, a timeline for next patient contact, focus areas for next contact, and background on the baseline referral. This information is essential for comprehensive documentation of a patient's SDOH and creates actionable data that can be picked up by KPNW Patient Navigators at any point throughout the patient experience.

A key feature of this SmartSet is the ability to track the status of each community resource referral. The tracking tool allows Patient Navigators and other staff members to track the status of SDOH referrals over time by documenting the results of follow-up contact between the patient and Patient Navigator (typically by phone or in-person during a subsequent health care visit), which are then pulled into an automated weekly report for review. The tracking 
SmartSet also provides an opportunity to document patient preferences about declining support for their SDOH. Without this integration, health systems are at risk of putting patients through unintended harm by screening for social needs without knowledge about whether the patient wants resource support, as well as the extent to which the patient has received the referred resource(s) over time.

Over the period June 2016- March 2019 KPNW providers made 18,684 community resource referrals for 7,888 unique patients to 6,506 community agencies, of which $23 \%$ resulted in the patients' identified SDOH being satisfied, partially satisfied or in progress (i.e., SDOH need was resolved). The most prevalent needs were, in order, medical support, food support, transportation support, housing support, and utilities support.

However given such a large number of referrals and a team of only 30 Patient Navigators, Patient Navigators face significant challenges in tracking the progress of referrals. Moreover, simply tracking the referral outcome on an excel spreadsheet does not address the factors that shape the actual referral outcomes. The ethnographic case studies below highlight the complexities involved in making a referral, connecting the member to appropriate resources, and achieving positive health outcomes. Through focusing on qualitative data from providers, I seek to provide insights into the everyday daily challenges involved in promoting access to social and community services as a means to address SDOH.

\section{Case Studies}

Case Study 1 
An example of the many forms of logistical suffering members and providers experience in service coordination is demonstrated in this case study. Last year, a KPNW Patient Navigator received a SDOH referral from a KPNW staff member about a patient who was undergoing cancer treatment, was uninsured (code z59.7), and had transportation needs (code z59.9). The Patient Navigator then contacted the patient by phone to understand their SDOH needs. When I asked why some members need a phone call to hear about resources, versus a letter or more passive outreach, the navigator explained:

I think in order to follow-up on resources that are just handed to you, you have to either have support in your family, or be pretty high functioning to be able to figure some of that stuff out.

The navigator further told me that this member was very overwhelmed with her recent diagnosis and "needed some extra advocacy from the care team."

During the initial discussion, the Patient Navigator discussed and prioritized the patient's needs, deciding that the first steps taken by the Patient Navigator would be to attempt to get the patient re-enrolled in Medicaid (i.e., Oregon Health Plan). For the navigator to build trust and rapport for the members she works with, she tells each member:

I can be their point of contact, I give them my direct phone number, so they don't have to go through the phone tree. And, anything they need, even from another department, or organization, they can call me and I can help coordinate it.

This navigator assumes the role of the main point of contact for the member. By calling the state Medicaid program and advocating for the patient as part of the patient's health care team, the navigator succeeded in getting health 
insurance reinstated through Medicaid and setting up the transportation benefit for the patient. These changes alleviated the patient's stress associated with not having health insurance coverage and transportation to their cancer treatment. And for this member, who "didn't have a lot of structure," having the navigator take on some of these logistical barriers helped her feel like she "did not have the whole world on [my] shoulders" and enabled the patient to focus on both getting to appointments and completing treatment.

However, semi-structured patient and provider interviews revealed the challenges involved in reducing social and logistical suffering. Dr. R, the Chief of Resource Stewardship at Sunnyside hospital used the example of treating members with congestive heart failure to demonstrate the complexities of addressing social needs within everyday care.

Well, I know the treatment algorithm for the COPD exacerbation and we can walk down that very effectively. We'll give them inhaling breathing treatments and maybe some steroids to help calm down inflammation in the lungs. And sometimes antibiotics are indicated. Oxygen as needed. And then we'll get them feeling a little bit better in a day or two. And hopefully get them home thereafter. And then try and look at maybe what drove that. Are they a smoker? Are they still smoking it? Have they been taking their inhalers?

I asked Dr. R how this treatment plan for this case might change if we had a better understanding of the member within a broader social, economic and environmental context.

If you took a broader view and looked at the patient, you might find a story that says, well that patient actually can't afford their inhalers because they lost their job six months ago. And so, they've been basically having to choose between pay for inhalers or groceries. Now maybe after being out of a job for six months, and they haven't been able to find work, they're on the verge of eviction. So, they may not have a place to stay. You can think 
about that and say, "While I may have solved an issue for the next day or two with the first option, if I take a broader view and say, "What does that look like a few months from now?" Well, we haven't solved the fact that it can't afford his prescriptions. We haven't solved that he might be on the verge of losing his housing.

Dr. A., the Chief of Home Health, echoing Farmer's theory of structural violence (Farmer 2001), further describes how SDOH exacerbate poor health outcomes and increase utilization of expensive medical services.

I have lots of examples of patients bouncing in and out of the emergency room and getting admitted. We had one recently, where the patient was on hospital discharge, and they were coming to our home health department. And we felt that the patient really wasn't able to participate in home health, and if they can't, then we're not supposed to keep them on service. It's a Medicare rule.

In my conversation with Dr. A, she expressed frustration with not being able to "break the red tape" and how regulatory rules and other mandates are not always in the best interest of either the patient or populations needs. I asked Dr. A what we might do as a system to help our members whose suffer from social and logistical barriers to care. In her response, she clearly articulated Kleinman's (1988) patient centered model and argued that we not only need this model, but we must operationalize it within our broader medical community, starting with a learning culture we can instill as leaders.

We really need a patient centered approach. And when we have successes, we start and end with the patient, and we stay with the patient needs until they no longer have those needs. So I think for me, it's about invigorating my colleagues to think outside of the box that they've been in for most of their career to be thinking about other parts of this patient. I think that's why I love what I do now because I don't know the answer but I know how to start asking the questions for our members. If we ask the right questions and help them, then we all win.

\section{Case Study 2}


My second case study provides an example of how anthropological theory and methods can help providers like Dr. A ask the right questions to identity and address underlying social and non-medical needs within a broader ecosystem of health care and community providers. $V$ is an 81 -year-old white man whose wife passed away a couple years ago. He lives alone and does not have adult children with whom he is well-connected. Before he retired, he worked as construction manager and was a self-proclaimed perfectionist. Mr. V was referred to the navigator because he had missed a couple of his appointments, and the physician, Dr. C, started asking different questions, such as, "Are there transportation issues?" and, "Is he socially isolated?"

Dr. C has been an internist at Kaiser Permanente East Interstate clinic for 17 years. When I interviewed him about the day-to-day challenges of caring for his patients, he opened up to me about social and non-medical barriers to care that often affect his patients' outcomes.

There are needs and issues that go beyond health care that are probably more relevant to a patient's needs and issues, as well as where they are in life. One of the big ones is social isolation. The funny part about it is some patients either call us or come to see us because they need the company. In a way, that's cute, but in a way, it's not who we are and it's a lot of resources to devote to that need. But it's a huge need. The UK now has a Minister of Loneliness and I read also that loneliness has the same cardiovascular risk as if you were a 15-cigarette smoker a day. So, in a way, loneliness is a health risk factor, but it's also a social issue that we're not, as a health care company, structured to address. That's not our charge.

When I asked Dr. C how he addresses these social issues for his patients, he referenced his broader care team, specifically his navigator. 
At least now we have a navigator. I can put in a message to my navigator, or referral, or just stop by her office and say, "Hey, I need some help," okay? At least, we have a process of how to address that, so I think, as an organization, we've gotten better in primary care to figure out how to address some of those needs.

In the case of Mr. V, Dr. C stopped by the office of Diana, a committed navigator who has a passion for writing and journalism and who told me she loves "learning about people and their stories." Diana assessed Mr. $V$ for social needs and discovered that he did have barriers to care due to lack of transportation, as well as needing help with activities of daily living such as bathing and help with laundry and cooking. When the navigator asked Mr., $\mathrm{V}$ if he would be interested in getting help with these needs, he refused, saying "I don't need that right now," and hung up.

When I asked Diana what she was going to do next, she responded with what Kleinman (1988) refers to as person-centered care.

I think there needs to be a respect for members declining support and it not being the right time to connect with any team whatsoever. And that doesn't mean we keep calling and we keep trying. It means that we know they're out there, they've been offered the support, and when they're ready, we trust that they will reach out to us.

Diana's approach to addressing this member's decision not to engage at this time showed that she truly met this member where he was and did not view him as "an obstacle." Additionally, because Diana employs a person-centered approach, she is able to build rapport with her colleagues and clinicians. They trust that they can not only refer to her, but that she will approach the member with respect and include them as active participants in their health and health care, rather than passive agents for information and referrals. 
Case Study 3

The traditional health care model in the United States is focused primarily on medical services. In this context, how might we deliver care more holistically and address the social and behavioral barriers to care? To answer this question, I had the opportunity to interview Dr. M, a family physician at the Rockwood clinic, where I observed her workflow with their clinic navigator, Jaime. Dr. M provided me the following orientation to the Rockwood clinic and the population she serves in the community.

Let me tell you a little bit about the community in which we live and practice in. There's over 70 languages spoken around that area. We're deemed a food swamp. You can go about 60 blocks before getting to a major grocery store. There are a lot of pockets of high crime. We're right next to the county clinic, so that environment really influences people's day-to-day. The most poignant stories to me are really the ones around homelessness and food and security. Like I said, I'm a family medicine doc but I've seen these problems across the age spectrum - families that struggle, seniors that struggle and the people that are in their sixties ready to retire, really struggling. That really worries me.

I then asked Dr. M to give me an example of a patient who had unmet social needs that affected their health outcomes.

I think of a gentleman who was in his 70's and had lost quite a bit of weight, about 20 pounds. We embarked on this workup to make sure there was nothing more serious causing his weight loss. One day I started asking him, "Tell me about your day. What are you eating?" That's when he confessed he only went grocery shopping once a month. They subsisted on canned food, and he and his wife were struggling. That was probably the root cause of his weight loss. He didn't have enough to eat.

Dr. $M$ was able to walk the member and his wife down the hall to see Jaime, the patient navigator. Jaime explained that this "warm handoff from the physician" is ideal, because he can meet with the member and family in real time and address 
their needs, and in this case Jaime was able to get this member set up with Meals on Wheels five days a week.

However, Jaime explained to me that there are many cases where a referral is not a viable solution for address social needs:

For the elderly population, when they stop driving, they're not able to access the clinic easily. They're not able to drive that 60 blocks to the grocery store. They live outside the service area for senior transport services. They're not able to access the free gym memberships that they need to keep healthy. They're not able to get to us. There is a population with unmet needs who we do not know about and cannot help.

This is an example of "logistical suffering" and what Farmer refers to as structural violence (Farmer 2001) The clinic may be set up with navigator resources and caring physicians like Dr. M who holistically assess their members' needs, but if a member cannot get to the clinic because they live outside the service area for public transport, or cannot use or do not know how to use social services, then these members suffer in silence.

I asked Dr. M how KPNW might remove some of the social and logistical barriers to care felt by our members. Her response beautifully illustrates the notion of community vitality - that Kaiser Permanente needs to work in partnership with a broader eco-system of community partners, and that the health care system cannot do this alone.

Talking and strengthening the partnerships we have within the organizations and really teaching our operational system how to engage with the community. I don't think we know how to do that very well. I think that's a huge opportunity. 
Discussion

As the three case studies demonstrate, KPNW is making an important first step in addressing SDOH within everyday care. Nonetheless, the expansion of this model throughout its health care system raises many challenges. To begin with, addressing social needs with a standardized assessment at the population level requires mass customization at the individual level. These adaptations include responding to member's living situation and their values, goals and personal preferences. All of this takes time and requires relationship building. Social and logistical suffering cannot be overcome if we do not consider the social, economic and political implications for the people of whom we are asking these questions and for whom we are offering support. Moreover, if health care delivery systems aim to understand people beyond their health needs, we could have the same danger of mis-labeling them as "non-compliant" with their social care plan as we do with members who cannot realize their medical care plan due to social and logistical barriers. If we do not change our model to leverage community partnerships and include them as partners in care, we will, as Nguyen and Peschard argue, "blame low-income populations for behaviors and subject them to interventions that medicalize social forms of suffering" $(2003,458)$.

Addressing SDOH requires developing effective workflows for referring members with identified SDOH to appropriate community resources and tracking the progress of such referrals to ensure needs are addressed. KPNW's approach relies on Patient Navigators to re-contact patients (primarily through follow-up phone calls) to determine whether they were able to access the community 
resources to which they were referred. These services require a great deal of time, and each week KPNW Patient Navigators screen hundreds of patients and make hundreds of new community resource referrals. In an interview with a navigator from Gateway clinic, she expressed feeling overwhelmed and the impact of this feeling on patient care:

We are constantly, as staff people, put under the constraints of time, and patients know it. And patients feel it. And I work in part with an older population of individuals, and taking time with them is a struggle on one part, because of time constraints, but then is also a very valuable way to engage and build relationships.

Anecdotally, KPNW Patient Navigators have observed increased SDOH resolution among patients enrolled in care management or similar programs that provide more "touch points" or opportunities for interaction between the patient and Patient Navigator within the health care setting. This workflow also provides an opportunity to collect data, both quantitative and qualitative, to learn about the information needs, barriers, and facilitators of the SDOH community resource referral process from the perspectives of the community organizations that serve as the resources, the patients who receive referrals, and health care team members who make referrals. Celia Higueras, the Health System Director at Oregon Community Health Worker Association, validates the critical need to "create the infrastructure so these different providers can refer to each other so it feels seamless for every single member" (personal communication with author, June 2016). Such work may inform the development of workflows that assess the impact of both community referrals and community connections, emphasize the value versus the volume of community referrals, and foster partnerships that 
could lead to the development of bi-directional communication channels between stakeholders to track the resolution of identified SDOH.

At the community level, establishing cross-sectoral partnerships with diverse social service organizations requires a broad range of resources to help patients and limit the burden on any single provider (Briar Ertz-Berger, personal communication with author, April 2018; Lindau et al. 2016). For example, KPNW has partnered with the Familias en Accion to deploy community health workers as extenders of the clinical care team. Higueras affirmed the importance of these strategic community partnerships and the critical role of community health workers and other traditional health workers in addressing members' needs.

Traditional health workers are a kind of workforce whose main value comes from the shared life experience that they have with the communities that they service. That peer-to-peer knowledge is really what creates trust and understanding so people can feel engaged in health care systems, social service agencies, and just be engaged to make the changes that they need to do. Traditional health workers also serve as an education bridge to health systems or social service systems to educate what are the real needs of the communities since they belong to those communities.

In this way, community health workers can activate latent community capacity and expand health care delivery beyond the licensed professional and exam room. Nonetheless, the current state of health care delivery may limit the optimizing of such community resources, as Higueras explains.

Community health workers have always existed because there have always been people helping their own communities. But the integration of that type of workforce into health care has been newer or a little bit more challenging because we still lack the infrastructure to do so. We're introducing a new workforce, and that takes time and remediation. It's not only one presentation. It's years of changing how systems work so they adopt a new type of workforce. 
A final obstacle to addressing SDOH through a member-centered and community partnership approach is establishing clear communication lines and workflows across health care staff roles and departments to facilitate quicker connections to resources for patients without confusion or duplication of services. A program manager who oversees an intensive case management team who works with a vulnerable population that are high utilizers of emergency room identifies opportunities within our own system to improve coordination and break down silos offer this assessment of the current situation.

I think one of the things we can do as an organization is really be clear about what resources we have in the region. I don't know how many times I discover a program down the hall from me that I didn't know existed that could be a resource for members that I'm working with. I think as much as we can break down the walls between our programs, whether that's mental health, addiction, primary care, care management, specialty support programs, I think we have to have our own well-connected network to truly be able to support our members. And if we don't have this network well established, it will be harder to connect with community partners and for them to connect with us, they will be in the same boat as our member trying to figure out how to navigate this vast web.

This assessment highlights that health care delivery is not only about how we interact with our members, but also interactions among health care providers and broader communities. Creating systems that build on community vitality can help health care systems flatten the hierarchy across patients, providers, teams, and organizations and re-enforce an ethic that all of these stakeholders are truly on the same team. 


\section{Chapter 3}

\section{Evaluation of a Targeted Navigator Pilot to Address Patient Medical Care Cost Concerns}

As the United States experiences rising health care prices and shifting health care policies, the out-of-pocket (OOP) costs that individuals and families must pay for health care have far outpaced wage growth (Claxton et al. 2017; Cuckler et al. 2018). In 2017, American workers with employer-based health insurance paid average annual premium contributions of $\$ 1,213$ for single coverage and $\$ 5,714$ for family coverage, in addition to annual deductibles of $\$ 1,505$ for single coverage and $\$ 2,645$ for family coverage (Claxton et al. 2017). At the same time, approximately one-third of American adults with health insurance report trouble affording their health insurance premiums and other OOP costs, $40 \%$ have difficulty affording their deductible, and nearly $25 \%$ worry about not being able to afford health care (DiJulio et al. 2017). Faced with difficulties paying for health care, many Americans decide to delay or skip recommended medical treatment or prescription medications due to costs (DiJulio et al. 2017; Zheng et al. 2017). Moreover, in order to pay their medical bills, over $70 \%$ of Americans report having to cut back on spending for necessities such as food, clothing and transportation, and $60 \%$ use up all of their savings (DiJulio et al. 2017). Taken together, it is estimated that SDOH account for as much as $40 \%$ of negative health outcomes (Booske et al. 2010; Krieger and Higgins 2002; Mansfield and Novick 2012; Woolf and Braveman 2011). This recognition has led to increased efforts to develop interventions that reduce medically-related financial hardship (Altice et al. 2017; American Society of 
Clinical Oncology 2017; Zafar 2015), as well as address social and economic needs - that is, the SDOH - within the health care delivery system (Gottlieb et al. 2016; Heiman and Artiga 2015).

A growing body of evidence suggests that social and economic needs interventions may help identify patients reduce the burden of basic social and economic needs by increasing connections with community resources (Fiscella, Tancredi, and Franks 2009; Garg et al. 2015; Gottlieb et al. 2016; Sarker et al. 2008). However, none of these studies report findings on the impact of the interventions on medically-related financial needs. This chapter analyzes KPNW's recent efforts to address this gap through a novel Financial Navigator $(\mathrm{FN}+)$ pilot project to address the medical care cost needs and concerns of patients in primary and specialty care within an integrated health care delivery system. I first describe the development of the program, then present the quantitative results from a pilot project to evaluate its preliminary perspective and conclude with a qualitative analysis of the pilot project using data from providers and patient interviews.

\section{The KPNW Financial Navigator Intervention}

As discussed in Chapter 2, Patient Navigators are an important part of the KPNW health care team and support members by identifying, prioritizing and addressing their non-medical social and economic needs. One of the most important non-medical identified needs identified through this work has been the question of the cost of medical care, and in particular members' knowledge of KPNW's Medical Financial Assistance Program and other community resources 
available to meet financial needs. In response, KPNW senior leaders developed the FN+ pilot (June to September 2016) to enhance the capacity of patient navigators to address patients' medical care cost needs and concerns. The project employed two-pronged approach: (1) providing enhanced training to one patient navigator to become the Financial Navigator and (2) building new capabilities within the EHR to enable health care staff to make referrals to the Financial Navigator. The Financial Navigator capacitation included a 40-hour training focused on medical care cost assistance resources, cost estimation tools, and health insurance benefits, as well as meetings with operational and clinical staff and leadership.

Following completion of a comprehensive training in June 2016, the Financial Navigator provided services at three clinical departments (Primary Care, Rheumatology, and Ophthalmology) at the East Interstate Medial Office, with a second medical office, Longview-Kelso, serving as the pilot study's control site. The intervention and comparison clinics were selected based on the presence of all three clinical departments operating within the same medical office. The pilot study also included a physician survey to gain provider insights on how having a designated Financial Navigator might affect the physicians' work and members' health outcomes.

Intervention participants were required to be age 18 or older at the time of the pilot, be an enrolled member at KPNW, have received medical care in one of the three participating departments at the intervention or comparison clinics, and have a medical care cost concern/need (e.g., unable to afford prescription 
medication). Patients who received care at the intervention clinic and reported a medical care cost concern/need to a health care team member (e.g., physician, nurse or other front-line health care staff member) were referred to the Financial Navigator via a staff message in their EHR. Next, the Financial Navigator attempted to contact the patient and invite them to participate, and patients who agreed to participate were then given the baseline survey. We then used the electronic health record to identify comparable patients with a visit to the one of the three participating clinical departments at the comparison clinic within the six months prior to the $\mathrm{FN}+$ pilot $(n=6,324)$. These patients were sent a secure email message inviting them to participate in the baseline survey. Comparison clinic participants were eligible for standard patient navigation services only and were provided a phone number to contact a patient navigator. Given the mode by which we identified comparison participants, we could not assess whether they reported their cost concern/need during their medical visit, nor whether they were referred to a patient navigator because of this cost concern/need.

\section{Data Collection and Measures}

Baseline and 30-day follow-up participant surveys were administered to assess: (1) social and economic needs; (2) satisfaction with medical care; and (3) satisfaction with cost concerns/needs assistance. The 30-day follow-up assessment included: (1) satisfaction with medical care; (2) satisfaction with cost concerns/needs assistance; and (3) satisfaction with navigation services (intervention only). For intervention participants, baseline survey administration was conducted either by phone or in-person by the Financial Navigator, while 
follow-up surveys were conducted by mail with paid return envelope or via REDCap Survey ${ }^{\mathrm{TM}}$ software. For comparison participants, both baseline and follow-up surveys were conducted using REDCap Survey ${ }^{\mathrm{TM}}$ software (Harris et al. 2009). Participants who did not complete the follow-up survey following initial contact were sent reminder emails one week after the initial attempt. For all participants who completed the baseline survey, the research team collected baseline patient sociodemographic and disease characteristics, including age at time of intervention, sex, race, Hispanic ethnicity, health plan type, length of enrollment in health plan, census-level household income, marital status, educational attainment, body mass index (BMI), Charlson Comorbidity score, and tobacco use. Physicians in the participating departments at both clinics were also invited to complete a survey to assess: (1) perceptions about the costs of medical care and treatment; (2) patient financial well-being; and (3) satisfaction with the financial navigator (physicians at intervention clinic only).

\section{Statistical Analysis}

The pilot study team used descriptive statistics to evaluate participants' demographic and clinical characteristics and survey response rates. Other than the section on social/economic needs, all items on the patient survey were presented on a 5-point Likert scale from $1=$ "Strongly Disagree" to $5=$ "Strongly Agree". For final analyses, we dichotomized responses (1 = "Agree" or "Strongly Agree"; 0 = "Neutral", "Disagree", or "Strongly Disagree") and evaluated differences using Chi-square tests. Ordinary least squares regression was used 
to assess change in member-reported satisfaction from baseline to 30-day follow-up, controlling for baseline values.

\section{Pilot Study Results}

\section{Participants}

213 patients were referred to the $\mathrm{FN}+$ pilot between August 1 and October $31,2016,97$ of whom completed the baseline survey ( $45.5 \%$ response rate). Twelve patients were excluded from the analysis due to ineligibility (e.g., not a KPNW member at the time of the pilot or did not receive care at intervention clinic), resulting in a final sample of $n=85$ intervention clinic participants. Among the approximately 374 patients who completed the baseline survey (6\% response rate), patients were defined as having a medical care cost concern/need if they reported any of the following financial or economic needs on the baseline survey: medical bills, treatment costs, or utility/bill pay. A sample of $n=51$ patients were identified as having a medical care cost concern/need and included in the comparison clinic cohort.

Most participants in both the intervention and comparison groups were female, non-Hispanic, and White. Nearly half of participants in both the intervention group (48\%) and comparison group (52\%) reside in an area with annual household incomes $<\$ 50,000$. Intervention participants were older (mean age $=66.5$ years $)$ and had lower mean BMI $\left(30.3 \mathrm{~kg} / \mathrm{m}^{2}\right)$ than comparison participants (mean age $=58.7$ years, mean $\mathrm{BMI}=34.6 \mathrm{~kg} / \mathrm{m}^{2}$ ). A low percentage of both intervention (15\%) and comparison (18\%) participants were tobacco users. Quantitative findings 
Baseline survey results. Forty percent of intervention participants and $24 \%$ of comparison participants reported having one or more non-medical social need at baseline (Table 3). Among those participants with one or more non-medical social need, the three most commonly reported needs among the intervention group were transportation (53\%), housing (38\%), and social activities (32\%), while for comparison group they were employment (33\%), food (33\%) and housing (33\%). Among the intervention participants, $41 \%$ reported that costs of medical care were important when choosing treatment and $41 \%$ reported that they were comfortable asking questions about the costs of medical care, compared to $84 \%(p<0.001)$ and $53 \%(p=0.212)$ of comparison participants, respectively. Seventeen percent of intervention participants and $43 \%$ of comparison participants reported that in the last year they have avoided or delayed medical care when sick because of cost $(p=0.001)$ Follow-up survey results. Among intervention participants, 93\% reported that their medical care team was "good at listening carefully to what I have to say" compared to $69 \%$ in the control group, and $31 \%$ reported that their medical care team "helped me cope with any uncertainty or unknowns related to costs," compared to $25 \%$ of comparison participants. Sixty-one percent of intervention participants, compared to $31 \%$ of comparison participants, reported getting answers to their questions about medical care costs. A greater percentage of intervention (62\%) than comparison (25\%) participants also reported satisfaction with assistance on questions and concerns about costs related to their medical care. As shown in Figure 3, intervention participants had significantly greater 
improvements in both the satisfaction with their medical care $(p=0.025)$ and the satisfaction with cost assistance $(p=0.013)$ at 30 -day follow-up, compared to comparison participants, controlling for baseline responses.

Physician survey results. Eleven physicians completed the survey (response rate $=16 \%$ of 70 possible respondents), all of whom agreed that cost influences their patients' decisions about medical care. Over $80 \%$ of the physician respondents reported that they were comfortable discussing costs of medical care/treatment and that they engage in these cost-of-care discussions with their patients. Ninety-one percent of physician respondents reported a belief that physicians have a responsibility to consider the impact of medical care on their patients' financial well-being, although only $18 \%$ of them reported having a sense of their patients' financial well-being (Figure 4).

Items on satisfaction with the financial navigator were asked of intervention clinic physicians only. Six of the eleven physicians who completed the survey were from the intervention clinic, and four had worked with the Financial Navigator during the intervention time. Among these four physicians, $75 \%$ were satisfied with both the Financial Navigator's overall responsiveness and timeliness in coordination of care, while $50 \%$ were satisfied with the Financial Navigator's awareness of appropriate resources. Additionally, physicians reported that the Financial Navigator was helpful in providing information to meet the needs of their patients $(75 \%)$, that the Financial Navigator worked with them to address their patients' concerns $(75 \%)$, that they would recommend the Financial Navigator to other patients in the health care 
system $(75 \%)$, and that they value financial navigation services as part of the health care system $(75 \%)$.

\section{Member Case Study}

To better understand the context of members' financial concerns, I did a deep dive chart review on members who had been referred to the financial navigator program. One member whose chart I reviewed was having difficulty paying unexpected medical bills. Like many members, he believed he was ineligible for services he might quality for, I wanted to know more about the context of his financial challenges. The pattern that triggered a Financial Navigator intervention was Mr. L's consistently missing his eye injections in ophthalmology for a rare degenerative eye condition. Without his injections, he would eventually go blind. A white man in his 40 s, Mr. L was employed by a large technology company in Oregon and looked at computers all day. He made a good salary at over $80 \mathrm{~K}$ per year. However, Mr. L had a lot of expenses. Between his rent, car lease, graduate school debts, gym membership, and a recent unexpected cost of helping his mother pay for long term care in an Alzheimer's facility, he was living close to pay check to pay check. And now, with an eye injection that cost him hundreds of dollars every month, he was struggling.

When the Financial Navigator met with Mr. L, there was not much she could do to help him. Mr. L made too much money to be eligible for any public assistance or entitlement program or KPNW medical financial assistance, even though well over $10 \%$ of his income were going towards his and his mother's 
health care need. Additionally, because of his age and rare condition, few community resources were available to offset his medical costs. As the navigator explained, for cases like this, finding resources is very challenging.

I feel like the resources and the information are kind of scattered about. They're like dots. There's a little piece here, there's a little piece there and my goal always is to try to connect those dots so that I have a deeper understanding of all the things that we can offer. And then when I don't have the things that we can offer from Kaiser, it's even broader to know how to get out to the community and find those resources as well.

Given these obstacles, the Financial Navigator and Mr. L discussed his options to save more money. With his transportation needs, he could not give up his car lease. His apartment was also "a good deal for Portland" and although his mother's institutional costs were high, he could not keep her at home safely as he was gone most of the day at work and commuting to work. Moreover, Mr. L was committed to maintaining his current activities - he wanted to work and be independent despite his condition and not become disabled,

I want to find ways that I don't end up in that way. And from Kaiser I would like to know that I have that kind of support and resources to make sure that I have the ability to have a healthy and fulfilling life when I get older.

If Mr. L continues to forgo his injections, he will eventually go blind. Once this happens, he will not be able to work. He will have to quit his job and go on Social Security Disability Insurance. His mother will also likely have to go on a public assistance program and be placed in a foster care home that may or may not be equipped to address her memory issues. Most likely, she will have many hospitalizations during this transition. 
The themes from this case study exemplify how our current health system exacerbates structural violence and logistical and social suffering, not only for Mr. $\mathrm{L}$, but also for his mother and tax payers whose premiums are soaring because health care costs are rising astronomically. If we had a system that could address the family health needs rather than simply those of the individual, Mr. L might be eligible for financial assistance and could continue to get his injections, support his mother in her memory care unit, and continue to be an active, working community member.

KPNW providers are increasingly accepting the idea that health extends beyond clinical conditions to include access to basic needs, socialization, and being part of a community. Yet as the following assessment from a Nurse Case Manager suggests, putting this vision into practice is not easy.

I'm starting to recognize the challenges of aging, myself. And within my own community. We have been spending a lot of time talking about that, the men and women that I spend a lot of time with. Like, how is this going to be for us in ten and twenty years? People end up in the emergency room because of caregiver burnout. I would like to see systems that include things like respite to give those care providers a break. What l'd like to see from Kaiser is those types of services that I just said. If I get to the point where I can't care for myself or if I need regular, consistent help, or continuous supervision to be at home, I would like services to help my care providers be able to take care of me for that long term so that they can also be happy and healthy and have their lives. We ask friends and family to do a lot. And, it's what's needed. But it's hard

For Mr. L, the community became this very kind of solution. The navigator recommended that Mr. L start a "GoFundMe" account to raise money to address his medical need since he had a rare disease, a situation that people may sympathize with. So Mr. L started a crowd-funded campaign on the site 
GoFundMe. Through the generous donations of people in his community, he raised over $\$ 12,000$, which will deeply off-set the injection costs. This is of course not a sustainable solution, but an example of how the community, through strong social capital, can reduce social and logistical suffering. People in Mr. L's community empathized with his situation and created a natural ecosystem of help beyond the available resource of the health system or government assistance programs. As health care delivery systems begin to measure the impact of addressing social determents as part of their social justice mission and an affordability imperative, it is critical that we also measure the level of comprehensive system capital, which can lift up the community as part of the solution rather than consider it a barrier that perpetuates health disparities.

\section{Reshaping Health Care to Address Medical Cost Concerns}

This chapter has highlighted the potential impact of a novel financial navigator pilot intervention to address patients' medical care cost needs and concerns within a real-world health care delivery setting. Participants who received the $\mathrm{FN}+$ intervention had greater improvements in both satisfaction with their medical care and satisfaction with cost assistance at 30-day follow-up than comparison participants. In addition, most physicians reported that they think it is important to discuss the costs of care and know the financial implications of medical care costs on their patients, although very few physicians knew about their patients' financial well-being. Importantly, they valued financial navigator services as part of the health care system. 
Of particular note is the study's finding of an apparent disconnect between providers' beliefs about the importance of medical care costs in the delivery of medical care and their understanding of individual patient's financial wellbeing. This could be due to many factors. First, the time available to discuss the complex topic of financial wellbeing during a routine office encounter is limited by the demands of immediate needs and meeting health plan priorities in terms of care delivery and performance metrics (Ubel, Abernethy, and Zafar 2013). Second, patients may not be willing to fully disclose financial hardship due to mistrust, pride or embarrassment (Bestvina et al. 2014; Hardee, Platt, and Kasper 2005; Irwin et al. 2014; Zafar et al. 2015). Third, evaluating a person's financial wellbeing may be difficult - it is one thing to balance a checkbook, but quite another to absorb an unexpected $\$ 10,000$ expense. Fourth, providers may be uncomfortable asking about finances, as it is outside of their formal training and the subject is still a little taboo if the patient does not bring it up themselves (Hardee, Platt, and Kasper 2005). Lastly, the provider may have little idea of the patient burden of the service, including the complexity of plans/benefits and accumulated expenses contributing to maximum out of pocket expenses (Hardee, Platt, and Kasper 2005; Ubel, Abernethy, and Zafar 2013).

Nevertheless, understanding patients' financial well-being by engaging in costs of care conversations is critical to reducing patient financial hardship (Henrikson et al. 2017) and may help reduce financial distress or uncertainty (Ubel, Abernethy, and Zafar 2013), and improve medical decision-making treatment (Bullock et al. 2012). 
The development of this delivery system pilot intervention was driven by the goals of mitigating medically-related financial hardship and reducing cost barriers to access among patients in both primary and specialty care settings. The FN+ intervention focused on enhancing existing resources within the health care system. For the Financial Navigator, the training on medical care cost assistance resources, cost estimation tools, and health insurance benefits was geared toward improving the overall knowledge and skillset required to work with, educate, and address patients' medical care costs, needs, and concerns. This is in addition to the standard navigation support of interacting with patients to identify, understand and meet their non-medical social or economic needs. Moreover, building new referral capabilities within the EHR and having the Financial Navigator connect with key clinical and operational staff led to novel operational workflows to connect with patients and coordinate care between health care staff. As evidenced by the intervention clinic physicians, they valued the financial navigator as part of the health care system.

These findings affirm other recent attempt to develop financially-focused patient navigator programs. For example, Shankaran et al. (2018) recently reported on an oncology-specific financial navigator pilot program designed to help improve patient knowledge about treatment costs, provide financial counseling, and help manage OOP expenses. Using an intervention-group-only design, patients at a single institution who were within 6 months of completing treatment for non-metastatic cancer were eligible to receive a financial education course, followed by monthly assistance from two external organizations (the 
Consumer Education and Training Services and the Patient Advocate Foundation) over a 6-month period. They found that patients most often needed assistance with budgeting, retirement planning, medical bill questions, as well as processing applications for appropriate insurance coverage, basic social and economic needs (e.g., housing, transportation), and disability (Shankaran et al. 2018). Approximately $83 \%$ of participants reported high satisfaction with the financial navigation program; however, there were no significant decreases in the proportion of participants who had debt accrual between baseline (55\%) and follow-up (57\%), or self-reported financial burden ( $45 \%$ at baseline and $43 \%$ at follow-up).

Collectively, findings from financial navigation pilots underscore certain key elements that may inform the development of future interventions to address medical-related financial hardship within the care setting. First, a comprehensive understanding of medical care costs, health insurance benefits, and medical financial assistance programs is essential for educating patients about their OOP costs for impending medical care and coordinating the resources to manage the financial implications. Further, as noted by Shankaran et al., the intervention “...must be provided in a manner that is acceptable, accessible, and minimally burdensome alongside clinical care" $(2018,24)$. Accordingly, developing workflows that enable physicians and other health care staff to readily identify a patient's financial concerns, needs, and capability within the clinical encounter and then engage in a "warm hand-off" to the appropriate non-clinical personnel or resources may minimize the burden on the clinical staff. Lastly, interventions 
aimed at addressing medical-related financial hardship may also need to incorporate how to address other unmet non-medical social needs, as demonstrated by the KPNW pilot project participants requiring assistance with both financial and non-financial social needs. 


\section{Chapter 4}

\section{Conclusion and Recommendations}

Screening and documenting basic needs and referring to communitybased organizations is not a panacea for reducing social and logistical suffering in the health care setting. Addressing social needs further requires that health systems employ person- and community-centered care, and this cannot only be a cohort of patient navigators, social workers or other non-medical staff. For example, if a provider is aware that a patient is homeless and needs a medication that requires refrigeration, the provider must think about how they can change or augment the clinical prescription to a medication that does not require refrigeration. An emergency room physician in KPNW gives another example of how SDOH data enables her to provide more holistic care.

When I see a frail and elderly person in the emergency room who has had a fall, I look on the problem list to see if they are food insecure. I not only ask them about their pain, I ask them if they have difficulty buying enough food to eat or cook for themselves. I now can not only make a referral to physical therapy or a fracture clinic, but I can also make a referral to [patient] navigators to ensure the patient has food, transportation, caregiver support, etc. (Briar Ertz-Berger, personal communication with author, April 2018)

Reducing the burden of patients' SDOH at the individual and population level will require a culture of health within communities to develop and maintain strong connections between health care systems and community-based organizations that address such needs. Developing successful, efficient approaches to making and maintaining these connections could bolster the community's capacity to fulfill patients' $\mathrm{SDOH}$ and foster future work that 
generates evidence that resolution of SDOH affects downstream health care use, costs, and health disparities. As an integrated health system committed to total health, KPNW cannot expect patients to manage their health or engage in behavior change if they do not have enough sufficient resources to eat healthfully, pay bills, or manage their daily responsibilities.

KPNW recently had a two-day event where over 200 leaders came to "reimagine care delivery," including 20 invited participants from various partner community-based organizations. These participants were asked to re-imagine a model of care that extends beyond clinical services and partners with agencies that address the social and non-medical needs of the community. The case studies presented in this thesis are only a few examples of the day-to-day challenges that members have and that providers encounter when trying to improve the health and well-being of the population. KPNW is at a pivotal moment where we are moving beyond our traditional definition of health into an expanded definition that includes social, economic, behavioral and spiritual wellbeing. And, more critically, KPNW recognizes that the organization cannot address the needs of members and the community without the community as part of the solution. This realization is leading to new contracts with communitybased organizations and deployment of new roles such as peer support specialists and community health workers who can help KNPW increase "cultural capital" across its care delivery system. All of this activity is evidence of a new culture of health that emphasizes cross sector collaboration and system capital. 
As part of this thesis project and my work at KPNW, our team created a toolkit to provide a standardized process for screening for social needs, a measurable and interoperable way to document social needs, a method for tracking of community resource referrals, and new roles and partnerships to enable cross-sector collaboration and coordination. This toolkit has been implemented in KPNW to spread and scale the navigator intervention across primary, specialty, emergency, and hospital care settings. At the same time, the toolkit, which includes documentation of best practices, training syllabus, escalation pathways, and core competences for a comprehensive navigation program, is being adopted and adapted across multiple Kaiser Permanente regions such as Colorado, Northern California, Southern California and Washington State. In this way, the toolkit allows for program fidelity and standardization so that Kaiser Permanente can have cross-regional learnings. In summary, health systems, providers, and patients agree that social needs and medical care costs are an important component of health care, but they are rarely addressed explicitly within the delivery setting. This thesis highlights the promise of a novel model and intervention designed to address social and medical care cost concerns and needs, as well as describing how socially-informed care may be delivered systematically to address cost needs, increase patient satisfaction, and, ultimately, improve health outcomes. As the American health care system continues to evolve with trends toward higher costs and greater cost-sharing, patients may increasingly be at financial risk and have greater social needs such as food insecurity and difficulty paying rent. 
Interventions that identify individuals who have the greatest need for assistance with socio-economic aspects of medical care may reduce the likelihood of social and logistical suffering and improve health equity. Furthermore, knowing that more and more community driven interventions are being geared to offset medical expenses, health systems must find a way to carefully integrate into these newly forming and fragile community eco-systems without overwhelming and over-burdening these networks. Instead, we must work to create altruistic and cross-sector collaborations between gig economy, health systems, social services, community and social capital to strengthen the ecosystem and improve health outcomes at individual, community and population levels. 
Table 1. Social Determinants of Health Data Collected in EHR, Corresponding ICD-10 Z-codes, and Examples of Use

\begin{tabular}{|c|c|}
\hline \multicolumn{2}{|c|}{ SDOH Domain: Social } \\
\hline Z-code & Examples of situation(s) to use Z-code \\
\hline Caregiver stress (Z63.8) & $\begin{array}{l}\text { Caregiver for child, adult, senior with complex me } \\
\text { and behavioral needs. }\end{array}$ \\
\hline Family stress (Z63.8) & $\begin{array}{l}\text { Social, economic, medical stressors affecting } \\
\text { family and/or home environment. }\end{array}$ \\
\hline $\begin{array}{l}\text { Insufficient social insurance or } \\
\text { welfare support (Z59.7) }\end{array}$ & $\begin{array}{l}\text { Lack of insurance, uninsured, or under-insured. } \\
\text { Needing SSI/SSD or public assistance. }\end{array}$ \\
\hline $\begin{array}{l}\text { Need assistance with community } \\
\text { resources ( } Z 74.8)\end{array}$ & $\begin{array}{l}\text { For general resources when there is not a } \\
\text { specific z-code for need }\end{array}$ \\
\hline $\begin{array}{l}\text { Unavailability or inaccessibility of } \\
\text { other helping agencies (Z75.4) }\end{array}$ & $\begin{array}{l}\text { Lack of community resources, ineligible for } \\
\text { community resources, no capacity. }\end{array}$ \\
\hline Social isolation (Z62.4) & $\begin{array}{l}\text { Lack of or limited availability of family, friends, } \\
\text { community groups or agencies to provide } \\
\text { routine social support. Member spends majority } \\
\text { of time alone (in home or facility). }\end{array}$ \\
\hline $\begin{array}{l}\text { Problems related to other legal } \\
\text { circumstances }(Z 62.5)\end{array}$ & $\begin{array}{l}\text { Health harming legal issues (guardianship or } \\
\text { custody issues, renter's rights, employment } \\
\text { rights, problems with income or public benefits, } \\
\text { legal status, disability). }\end{array}$ \\
\hline $\begin{array}{l}\text { Problems related to release from } \\
\text { prison }(Z 62.5)\end{array}$ & $\begin{array}{l}\text { Transition to work, access to health services, } \\
\text { housing. }\end{array}$ \\
\hline \multicolumn{2}{|c|}{ SDOH Domain: Economic } \\
\hline Z-code & Examples of situation(s) to use Z-code \\
\hline Financial problem (Z59.9) & $\begin{array}{l}\text { Financial worries. Difficulty paying for basic } \\
\text { needs- food, clothing, medical care, utility, rent, } \\
\text { bills, at risk of debt, etc. }\end{array}$ \\
\hline Food insecurity (Z59.4) & $\begin{array}{l}\text { Worry about finding affordable food. Food } \\
\text { stamps running out. Lack of fresh fruits and } \\
\text { vegetables available. }\end{array}$ \\
\hline Homelessness (Z59.0) & Camping, sleeping in shelter, couch surfing etc. \\
\hline $\begin{array}{l}\text { Housing or economic circumstance } \\
\text { (Z59.9) }\end{array}$ & $\begin{array}{l}\text { At risk of homelessness - inability to pay rent, } \\
\text { inability to find affordable or permanent } \\
\text { housing, rent increases etc. }\end{array}$ \\
\hline $\begin{array}{l}\text { Inadequate material resources } \\
(\text { Z59.9) }\end{array}$ & $\begin{array}{l}\text { Lack of transportation, clothing, computer, } \\
\text { phone, housing/hygiene goods, school } \\
\text { supplies, working appliances, basic goods. }\end{array}$ \\
\hline $\begin{array}{l}\text { Intentional underdoing of medication } \\
\text { due to financial stressors (Z91.120) }\end{array}$ & $\begin{array}{l}\text { Not taking medications, not filling prescriptions, } \\
\text { intentionally under-dosing medications, etc. due } \\
\text { to financial strain }\end{array}$ \\
\hline Unemployment (Z56.0) & $\begin{array}{l}\text { Unemployed, unable to find work, } \\
\text { underemployed. }\end{array}$ \\
\hline
\end{tabular}




\begin{tabular}{|l|l|}
\hline Low income (Z59.6) & $\begin{array}{l}\text { Not enough money to pay for necessities, has } \\
\text { just enough to make ends meet, poverty line } \\
\text { and under }\end{array}$ \\
\hline \multicolumn{1}{|c|}{ SDOH Domain: Environmental } \\
\hline Fall risk (Z91.81) & \multicolumn{1}{|c|}{ Examples of situation to use Z-code } \\
\hline Stressful work schedule (Z56.3) & $\begin{array}{l}\text { Does not want to use devices to help with } \\
\text { walking, unsteady gait, poor housing conditions } \\
\text { (hoarding, deteriorating floors, rugs) }\end{array}$ \\
\hline Foster care status (Z62.21) & $\begin{array}{l}\text { Working multiple jobs, physically strenuous } \\
\text { jobs, night shifts, long shifts, etc. }\end{array}$ \\
\hline $\begin{array}{l}\text { Problem related to social } \\
\text { environment (Z62.9)(Z62.9) }\end{array}$ & $\begin{array}{l}\text { Living alone, living in clutter (hoarding) } \\
\text { dangerous or health harming environment }\end{array}$ \\
\hline \multicolumn{1}{|c|}{ SDOH Domain: Health Education } \\
\hline $\begin{array}{l}\text { Dental well care counseling } \\
\text { (Z71.89) }\end{array}$ & $\begin{array}{l}\text { Educating members on dental care benefit } \\
\text { (Medicaid) and access to free or low-cost } \\
\text { dental services }\end{array}$ \\
\hline $\begin{array}{l}\text { Referral to county mental health } \\
\text { agency (Z68.81) }\end{array}$ & $\begin{array}{l}\text { Educating member on community mental } \\
\text { health organization, helping members schedule } \\
\text { visit }\end{array}$ \\
\hline $\begin{array}{l}\text { Illiteracy and low-level literacy } \\
\text { (Z55.0) }\end{array}$ & $\begin{array}{l}\text { Educating member on how to navigate Kaiser. } \\
\text { Helping member with follow up instructions, } \\
\text { education etc. }\end{array}$ \\
\hline $\begin{array}{l}\text { Nutrition and exercise counseling } \\
\text { (Z71.3) }\end{array}$ & $\begin{array}{l}\text { Educating members on low cost gyms, silver } \\
\text { and fit, community centers, community cooking } \\
\text { classes, farmer's markets }\end{array}$ \\
\hline
\end{tabular}


Table 2: Core Interview Questions for All Stakeholders

\section{CORE Questions for ALL Stakeholders}

1. Can you tell us about your role and how it intersects with the organization?

2. What are your thoughts on KP's role in screening for and addressing member social needs? What value will it bring?

a. How if at all does this fit into KP's strategic agenda? (probe: quality, equity, community etc.)

b. What would be the benefit to KP? To clinicians/ frontline staff? To our members? To the community?

c. How, if at all, do you see this work aligning with other national, regional or local initiatives?

3. What do you believe should be the strategic focus addressing social needs? What do you see as the key priorities?

a. If you had to choose one key aim - is the aim of this work to improve quality of care or overall well-being? Reduce costs/improve affordability? Achieve health equity? Or something else?

b. What populations do you think would benefit the most? Why?

c. What specific social needs do you think are of highest concern (frequency / prevalence) in your region? (Probe: food, housing, adverse childhood experiences) How might these needs be different from the needs in other clinics?

4. What short, medium and long-term outcomes are you hoping to see from the implementation of social needs screening?

a. How long do you think it will take to realize these outcomes? What does success look like in 3 years? 6 years and beyond?

b. How confident are you that addressing social needs will reduce cost and/or utilization, at least for a specific subgroup of patients? 
Table 3: Member Needs at Baseline

\begin{tabular}{|c|c|c|c|}
\hline \multicolumn{4}{|c|}{ Member Needs at Baseline } \\
\hline Type of Need & $\begin{array}{l}\text { Longview / Kelso } \\
\qquad(\mathrm{N}=51)\end{array}$ & $\begin{array}{c}\text { Interstate } \\
(\mathrm{N}=22)\end{array}$ & $\begin{array}{l}\text { Intervention Other* } \\
\qquad(\mathrm{N}=64)\end{array}$ \\
\hline $\begin{array}{l}\text { Medical Cost } \\
\text { Needs Only }\end{array}$ & $28 \%$ & $24 \%$ & $24 \%$ \\
\hline $\begin{array}{l}\text { Medical Cost }+ \\
\text { One or More } \\
\text { Additional Needs }\end{array}$ & $72 \%$ & $77 \%$ & $76 \%$ \\
\hline $\begin{array}{l}\text { Top Non-Medical } \\
\text { Cost Needs }\end{array}$ & $\begin{array}{ll}\text { 1) Managing Health } \\
\text { Issues } \\
\text { 2) Vision/Hearing } \\
\text { 3) } \text { Managing Stress } \\
\end{array}$ & $\begin{array}{ll}\text { 1) } & \text { Dental Care } \\
\text { 2) Vision/Hearing } \\
\text { 3) } \text { Managing Stress }\end{array}$ & $\begin{array}{l}\text { 1) Vision/Hearing } \\
\text { 2) Dental Care } \\
\text { 3) Transportation }\end{array}$ \\
\hline
\end{tabular}

${ }^{*}$ Intervention Other included inviduals who participated in the financial navigator pilot and received financial navigation services, but did not receive medical care at the Intervention Clinic (Interstate) or may have been new KP members 
Figure 1. Community Resource Referral SmartSet: ICD-10 Z-Codes - Social Diagnoses

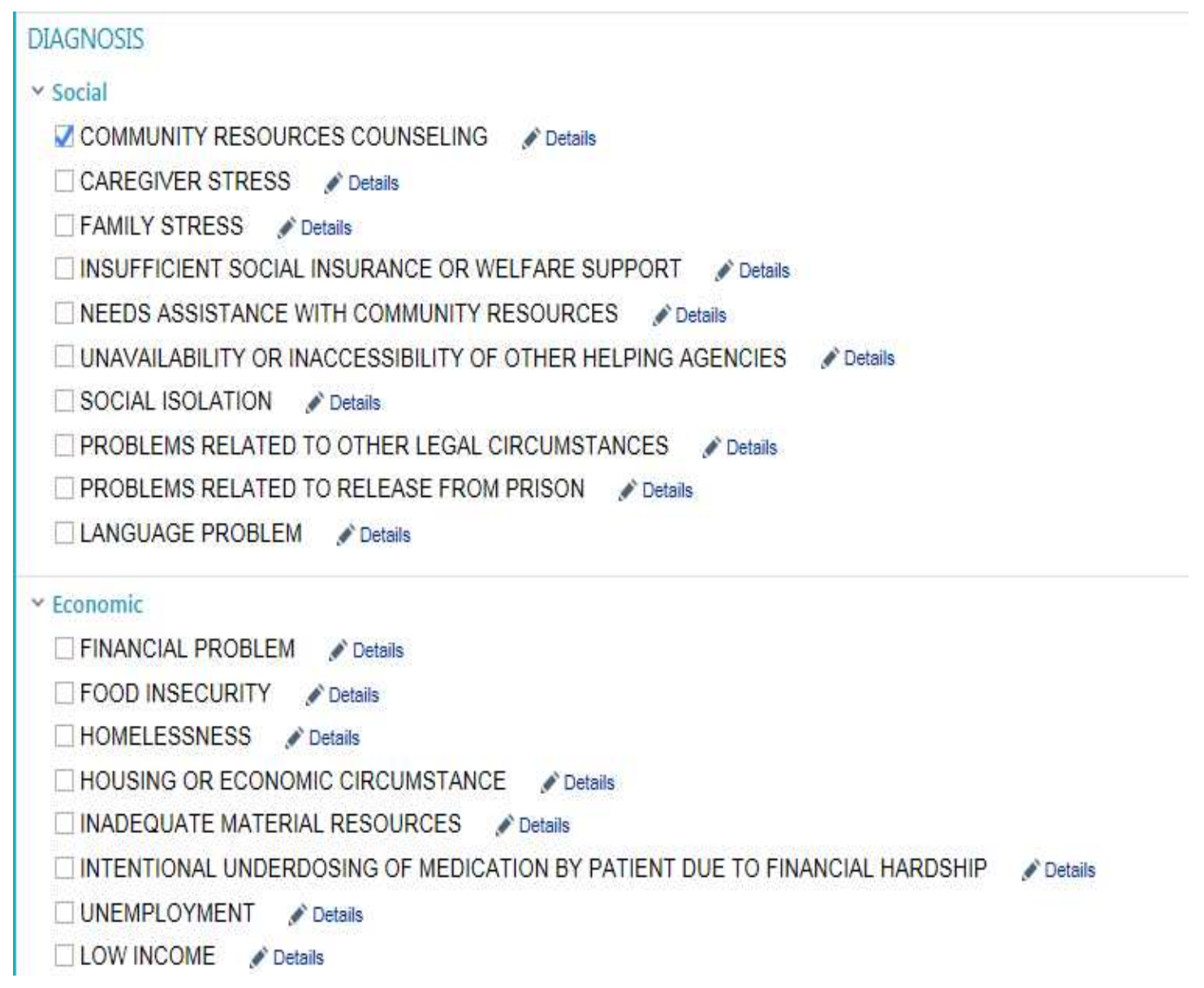


Figure 2. Navigator Workflow

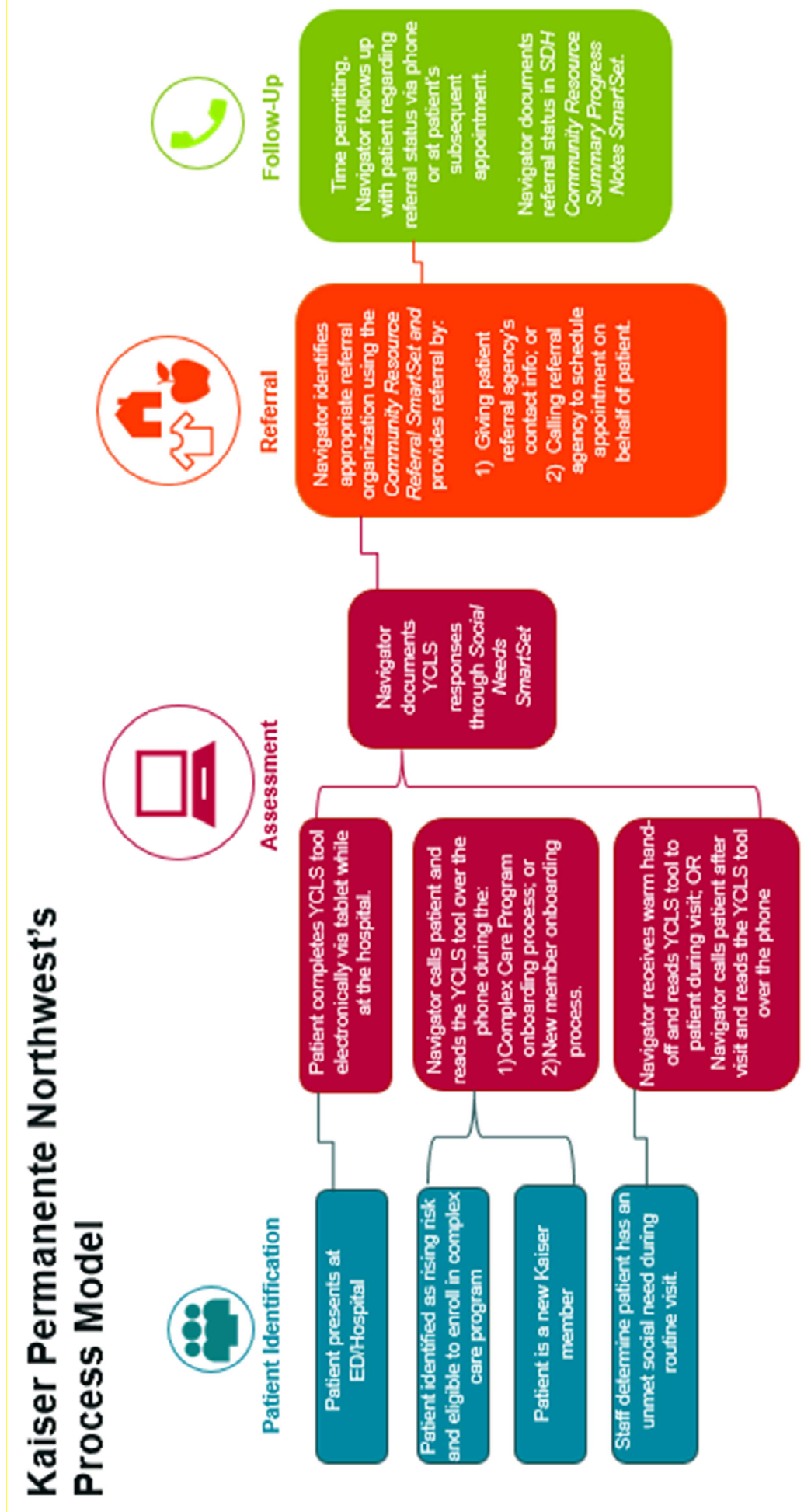


Figure 3: Impact of Financial Health Pilot on Member Satisfaction

\section{Impact of Financial Health Pilot on Member Satisfaction}

Satisfaction with Care

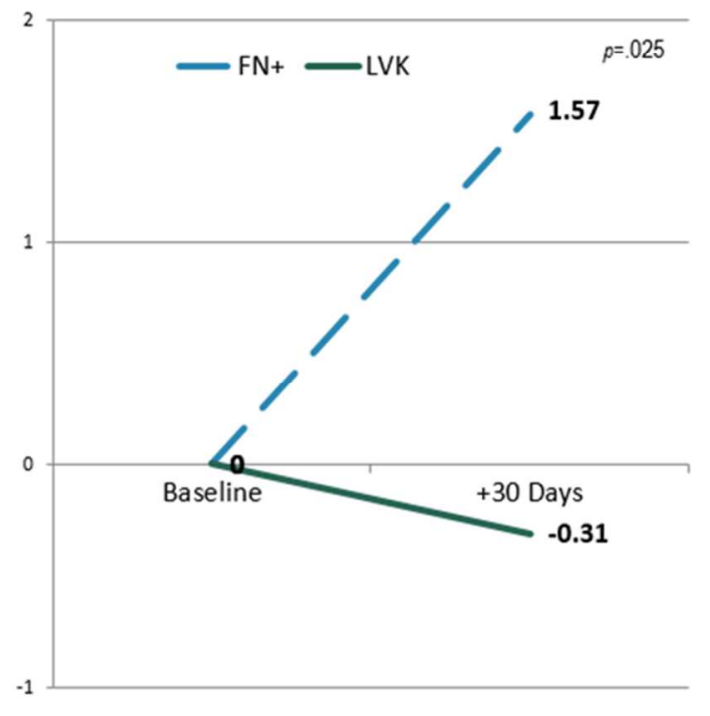

Satisfaction with Cost Assistance

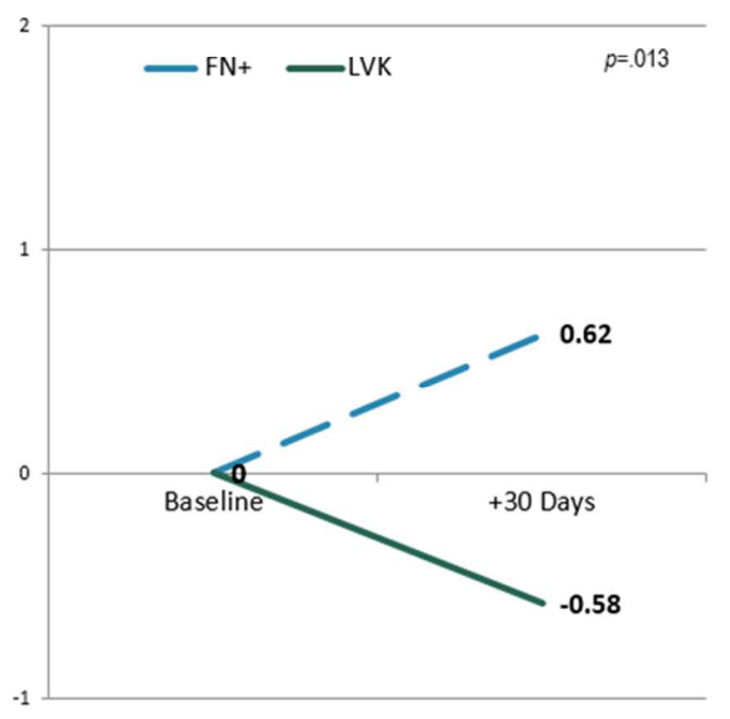


Figure 4. Provider Opinions on Member Medical Costs

\section{Provider Opinions on Member Medical Costs}

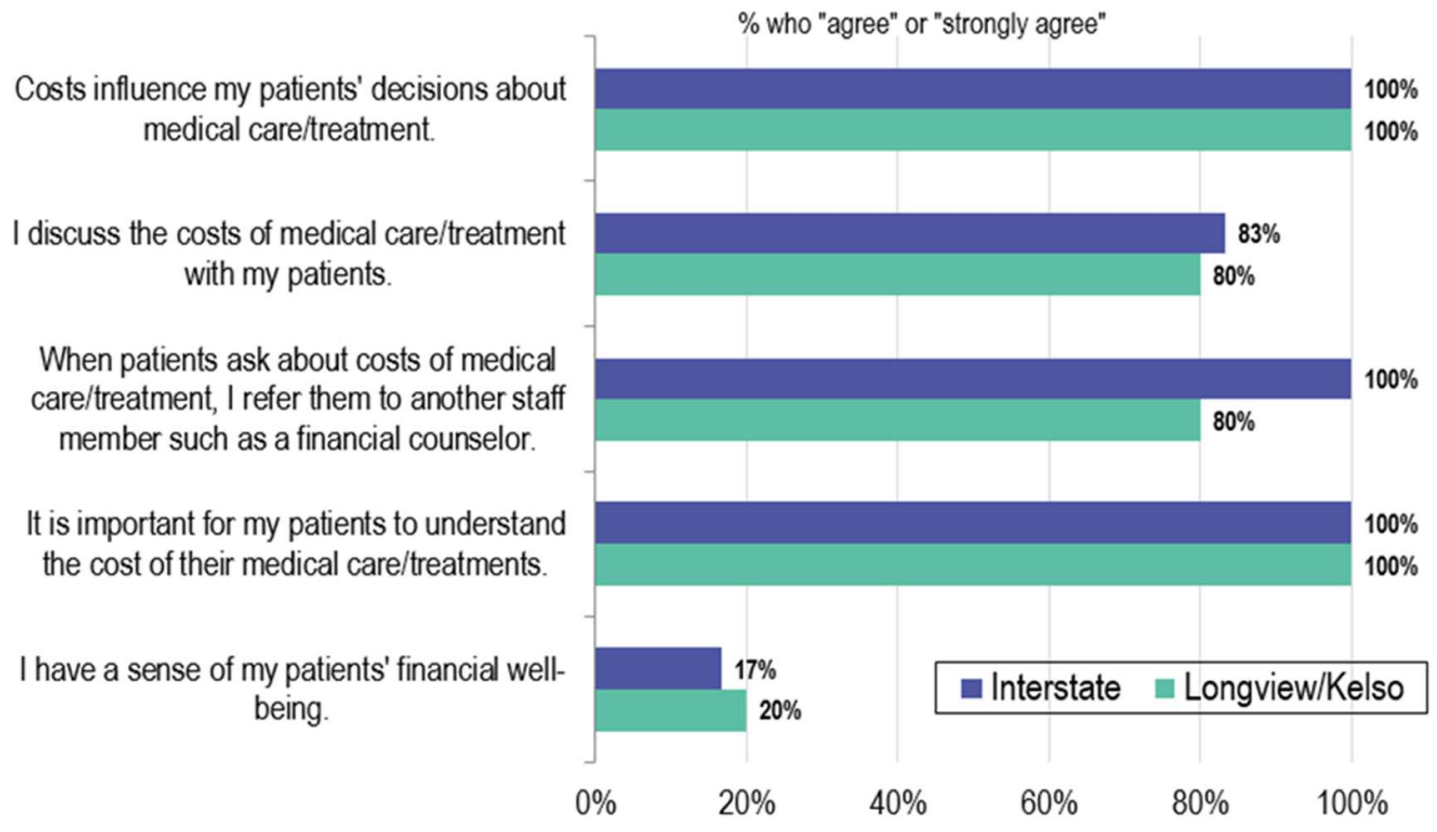




\section{References}

Altice, Cheryl K., Matthew P. Banegas, Reginald D. Tucker-Seeley, and K. Robin Yabroff. 2017. "Financial Hardships Experienced by Cancer Survivors: A Systematic Review." Journal of the National Cancer Institute 109 (2): djw205. http://dx.doi.org/10.1093/jnci/djw205

American Society of Clinical Oncology. 2017. "The State of Cancer Care in America, 2017: A Report by the American Society of Clinical Oncology." Journal of Oncology Practice 13 (4): e353-e94. http://dx.doi.org/10.1200/JOP.2016.020743.

Artiga, Samantha, Jennifer Tolbert, and Petri Ubri. 2017. "How do Health Care Costs fit into Family Budgets? Snapshots from Medicaid Enrollees." Menlo Park, CA: Kaiser Family Foundation.

Bestvina, Christine M., Leah L. Zullig, Christel Rushing, Fumiko Chino, Gregory P. Samsa, Ivy Altomare, James Tulsky, Peter Ubel, Deborah Schrag, Jon Nicolla, Amy P. Abernethy, Jeffrey Peppercorn, and S. Yousuf Zafar. 2014. "Patient-Oncologist Cost Communication, Financial Distress, and Medication Adherence." Journal of Oncology Practice 10 (3): 162-167.

Booske, Bridget C., Jessica K. Athens, David A. Kindig, Hyojun Park, and Patrick L. Remington. 2010. Different Perspectives for Assigning Weights to Determinants of Health. Madison, WI: University of Wisconsin, Population Health Institute.

Bullock, Andrea J., Erin W. Hofstatter, Melinda L. Yushak, and Mary K. Buss. 2012. "Understanding Patients' Attitudes Toward Communication About the Cost of Cancer Care." Journal of Oncology Practice 8 (4): e50-e58. http://dx.doi.org/10.1200/JOP.2011.000418

Centers for Medicare and Medicaid Services and National Center for Health Statistics. 2014. ICD-10-CM Official Guidelines for Coding and Reporting: FY 2016. Department of Health and Human Services.

Claxton, Gary, Larry Levitt, Michelle Long, and Erik Blumenkranz. 2017. "Increases in cost-sharing payments have far outpaced wage growth." Menlo Park, CA: Kaiser Family Foundation.

Claxton, Gary, Matthew Rae, Michelle Long, Anthony Damico, Gregory Foster, and Heidi Whitmore. 2017. Employer Health Benefits: 2017 Annual Survey. Menlo Park, CA: Kaiser Family Foundation; Chicago, IL: Health Research \& Educational Trust. 
Claxton, Gary, Matthew Rae, Michelle Long, Anthony Damico, Heidi Whitmore, and Gregory Foster. 2018. "Health Benefits In 2017: Stable Coverage, Workers Faced Considerable Variation in Costs." Health Affairs 36 (10): 1838-1847.

Cuckler, Gigi A., Andrea M. Sisko, John A. Poisal, Sean P. Keehan, Sheila D. Smith, Andrew J. Madison, Christian J. Wolfe, and James C. Hardesty. 2018. "National Health Expenditure Projections, 2017-26: Despite Uncertainty, Fundamentals Primarily Drive Spending Growth." Health Affairs 37 (3): 482-492. http://dx.doi.org/10.1377/hlthaff.2017.1655.

DiJulio, Bianca, Ashley Kirzinger, Bryan Wu, and Mollyann Brodie. 2017. Data Note: Americans' Challenges with Health Care Costs. Menlo Park, CA: Kaiser Family Foundation.

Dusetzina, Stacie B., Aaron N. Winn, Gregory A. Abel, Haiden A. Huskamp, and Nancy L. Keating. 2014. "Cost Sharing and Adherence to Tyrosine Kinase Inhibitors for Patients with Chronic Myeloid Leukemia." Journal of Clinical Oncology 32 (4): 306-311.

Farmer, Paul. 2001. "An Anthropology of Structural Violence." Current Anthropology 45(3): 302-323.

Fiscella, Kevin, Daniel Tancredi, and Peter Franks. 2009. "Adding Socioeconomic Status to Framingham Scoring to Reduce Disparities in Coronary Risk Assessment." American Heart Journal 157 (6): 988-994.

Fraze, Taressa, Valerie A. Lewis, Hector P. Rodriguez, and Elliott S. Fisher. 2016. "Housing, Transportation, and Food: How ACOs Seek to Improve Population Health by Addressing Nonmedical Needs of Patients." Health Affairs 35 (11): 2109-2115.

Garg, Arvin, Sarah Toy, Yorghos Tripodis, Michael Silverstein, and Elmer Freeman. 2015. "Addressing Social Determinants of Health at Well Child Care Visits: A Cluster RCT." Pediatrics 135 (2): e296-e304. http://dx.doi.org/10.1542/peds.2014-288.

Gold, Rachel, Erika Cottrell, Arwen Bunce, Mary Middendorf, Celine Hollombe, Stuart Cowburn, Peter Mahr, and Gerardo Melgar. 2017. "Developing Electronic Health Record (EHR) Strategies Related to Health Center Patients' Social Determinants of Health." The Journal of the American Board of Family Medicine 30 (4): 428-447. 
Gottlieb, Laura, Rachel Tobey, Jeremy Cantor, Danielle Hessler, and Nancy E. Adler. 2016. "Integrating Social and Medical Data to Improve Population Health: Opportunities and Barriers." Health Affairs 35 (11): 2116-2123.

Hamel, Liz, Mira Norton, Karen Pollitz, Larry Levitt, Gary Claxton, and Mollyann Brodie. 2016. The Burden of Medical Debt: Results from the Kaiser Family Foundation/New York Times Medical Bills Survey. Menlo Park, CA: Kaiser Family Foundation.

Hardee, James T., Frederic W. Platt, and llene K. Kasper. 2005. "Discussing Health Care Costs with Patients: An Opportunity for Empathic Communication." Journal of General Internal Medicine 20 (7): 666-669.

Harris, Paul A., Robert Taylor, Robert Thielke, Jonathon Payne, Nathaniel Gonzalez, and Jose G. Conde. 2009. "Research Electronic Data Capture (REDCap): A Metadata-Driven Methodology and Workflow Process for Providing Translational Research Informatics Support." Journal of Biomedical Informatics 42 (2): 377-381.

Heiman, Harry J., and Samantha Artiga. 2015. Beyond Health Care: The Role of Social Determinants in Promoting Health and Health Equity. Menlo Park, CA: Kaiser Family Foundation.

Henrikson, Nora B., Eva Chang, Kevin Ulrich, Deborah King, and Melissa L. Anderson. 2017. "Communication with Physicians about Health Care Costs: Survey of an Insured Population." The Permanente Journal 21: 1607. http://dx.doi.org/10.7812/TPP/16-07.

Irwin, Blair, Gretchen Kimmick, Ivy Altomare, P. Kelly Marcom, Kevin Houck, S. Yousuf Zafar, and Jeffrey Peppercorn. 2014. "Patient Experience and Attitudes Toward Addressing the Cost of Breast Cancer Care: Supplemental Data." The Oncologist 19 (11): 1135-1140.

Kleinman, Arthur. 1988. The Illness Narratives: Suffering, healing and the Human Condition. New York, NY, US: Basic Books.

Krieger, James, and Donna L. Higgins. 2002. "Housing and Health: Time Again for Public Health Action." American Journal of Public Health 92 (5): 758768.

Lindau, Stacy T., Jennifer Makelarski, Emily Abramsohn, David G. Beiser, Veronica Escamilla, Jessica Jerome, Daniel Johnson, Abel N. Kho, Karen K. Lee, Timothy Long, and Doriane C. Miller. 2016. "CommunityRx: A Population Health Improvement Innovation That Connects Clinics to Communities." Health Affairs 35 (11): 2020-2029. 
Mansfield, Christopher, and Lloyd F. Novick. 2012. "Poverty and Health: Focus on North Carolina." North Carolina Medical Journal 73 (5): 366-373.

Multnomah County Health Department. 2014. 2014 Report Card on Racial and Ethnic Disparities. Retrieved from https://multco.us/file/37530/download.

National Academies of Sciences, Engineering, and Medicine. 2017. Accounting for Social Risk Factors in Medicare Payment. Washington, DC: National Academies Press.

Nguyen, Vinh-Kim and Peschard, Karine. 2003. Anthropology, Inequality and Disease. Annual Review of Anthropology 32(447-474).

Rose, Nikolas. 2006. "Governmentality." Annual Reviews of Law and Society. 2(83-104).

Sarkar, Urmimala, John D. Piette, Ralph Gonzales, Daniel Lessler, Lisa D. Chew, Brendan Reilly, Jolene Johnson, Melanie Brunt, Jennifer Huang, Marsha Regenstein, and Dean Schillinger. 2008. "Preferences for SelfManagement Support: Findings from a Survey of Diabetes Patients in Safety-Net Health Systems." Patient Education and Counseling 70 (1): 102-110.

Shankaran, Veena, Tony Leahy, Jordan Steelquist, Kate Watabayashi, Hannah Linden, Scott Ramsey, Naomi Schwartz, Karma Kreizenbeck, Judy Nelson, Alan Balch, Erin Singleton, Kathleen Gallagher, and Karen Overstreet. 2017. "Pilot Feasibility Study of an Oncology Financial Navigation Program." Journal of Oncology Practice 14 (2): e122-e129. http://dx.doi.org/10.1200/JOP.2017.024927.

Simmons, W., \& Casper, M. (2012). "Culpability, Social Triage, and Structural Violence in the Aftermath of Katrina." Perspectives on Politics, 10(3), 675686. doi:10.1017/S1537592712001697

Ubel, Peter A., Amy P. Abernethy, and S. Yousuf Zafar. 2013. "Full Disclosure: Out-of-Pocket Costs as Side Effects." New England Journal of Medicine 369 (16): 1484-1486.

Urban League of Portland. 2015. State of Black Oregon. Retrieved from https://ulpdx.org/advocacy-and-public-policy/publication_archive/state-ofblack-oregon-2015/view-state-of-black-oregon-document/ 
Vanderwarker, Amber and Douglas D. Wilson. 2016. The Archeology of Food and Warfare: Food Insecurity in Prehistory. Switzerland: Springer International Publishing.

Weil, A. 2017 (January 23). "Culture of Health." Retrieved from http://www.healthaffairs.org/culture-of-health/

Woolf, Steven H., and Paula Braveman. 2011. "Where Health Disparities Begin: The Role of Social and Economic Determinants-And Why Current Policies May Make Matters Worse". Health Affairs 30 (10): 1852-1859.

World Health Organization. N.d. Social Determinants of Health. Retrieved March 17, 2019, from http://www.who.int/social_determinants/en/

Zafar, S. Yousuf. 2015. "Financial Toxicity of Cancer Care: It's Time to Intervene." Journal of the National Cancer Institute 108 (5): djv370. http://dx.doi.org/10.1093/jnci/djv370.

Zafar, S. Yousuf, Fumiko Chino, Peter A. Ubel, Christel Rushing, Gregory Samsa, Ivy Altomare, Jonathan Nicolla, Deborah Schrag, James A. Tulsky, Amy P. Abernethy, and Jeffery M. Peppercorn. 2015. "The Utility of Cost Discussions Between Patients with Cancer and Oncologists." The American Journal of Managed Care 21 (9): 607-615.

Zheng, Zhiyuan, Xuesong Han, Gery P. Guy Jr, Amy J. Davidoff, Chunyu Li, Matthew P. Banegas, Donatus U. Ekwueme, K. Robin Yabroff, and Ahmedin Jemal. 2017. "Do Cancer Survivors Change Their Prescription Drug Use for Financial Reasons? Findings from a Nationally Representative Sample in the United States." Cancer 123 (8): 1453-1463. 
Appendix A. Your Current Life Situation Questionnaire Your Current Life Situation (Shorter Form - revised for phone administration)

I'm going to ask you for some information to help us better understand you and your current situation. We ask for this information from all members referred to our service because it helps us provide care and advice and also to identify people who need some help with issues of daily living. If you need help, we may be able to refer you to Kaiser Permanente and community resources.

1. What is your current living situation? (Probes: Do you live alone or with other people? Is this situation short term or long term?; If already known that person is in a residential or nursing facility, just confirm with person what their medical record indicates)

Live alone in my own home (house, apartment, condo, trailer, etc.); may have a pet Live in a household with other people

$\square$ Live in a residential facility where meals and household help are routinely provided by paid staff (or could be if requested)

Live in a facility such as a nursing home which provides meals and 24-hour nursing care Temporarily staying with a relative or friend

Temporarily staying in a shelter or homeless

Other

2. Do you have any concerns about your current living situation, like housing conditions, safety, and costs?

$\square$ Yes $\rightarrow \quad \begin{aligned} & \text { Are these concerns about housing conditions, ability to pay for housing or } \\ & \square \text { No } \\ & \text { utilities, feeling safe, lack of more permanent housing, or something else? } \\ & \square \text { Condition of housing } \quad \square \text { Lack of more permanent housing } \\ & \square \text { Ability to pay for housing or utilities } \quad \square \text { Feeling safe } \quad \square \text { Other }\end{aligned}$


3. I'm going to read you a short list of things that people sometimes have trouble paying for. Please tell me whether in the past 3 months, you have had trouble paying for any of these things:

$\square$ Food $\quad \square$ Housing $\quad \square$ Heat and electricity $\quad \square$ Medical needs $\square$ Transportation

Childcare $\square$ Debts $\square$ Other $(\square$ None of these )

4. In the past 3 months, how often have you worried that your food would run out before you had money to buy more? Would you say Never, Sometimes, Often, or Very Often?

Never $\square$ Sometimes $\square$ Often $\square$ Very often

5. a. Has lack of transportation kept you from medical appointments or from getting medications?

b. Has [lack of transportation] kept you from doing other things you need to do for daily living?

Kept from medical appointments or from getting medications

Kept from doing things needed for daily living (e.g., shopping, errands, work, visiting people)

Transportation not a problem

6. If for any reason you need help with activities of daily living such as bathing, preparing meals, shopping, managing finances, etc., do you get the help that you need? (Probe to select a response below)
Don't need
any help
I get all the
help I need
I could use a
little more help
I need a lot
more help

7. In the last month, how often have you felt difficulties were piling up so high that you could not overcome them? Would you say Never, Almost never, Sometimes, Fairly often, or Very often?
Never
Almost never
$\square$ Sometimes
$\square$ Fairly often
$\square$ Very often 
8. This is the last question I need to ask. I'm going to read you a list of things that people sometimes need help with. You may not need or want help with any of these things. However, if you do, we may be able to suggest ways to get the help you need. (Read all and indicate ALL that apply)

$\square$ Food

$\square$ Housing (e.g.

Transportation

Utilities (heat, electricity, water, etc.)

Medical care, medicine, medical supplies

Dental services

Vision services

Applying for public benefits (WIC, SSI,

SNAP, etc.)

Interviewer: Who answered these questions?

Member alone $\square$ Member with someone's help $\square$ Family member, friend, or caregiver of member
Help with activities of daily living

Childcare/other child-related issues

$\square$ Debt/loan repayment

$\square$ Legal issues

$\square$ Employment

Other

I don't want help with any of these

YCLS v.2.0 (shorter form of YCLS 2.0 version 11-10-16 for phone interview) (v11-16-16) KPNatl 